\title{
Micromechanics of Dentin: Review
}

\author{
S. Seyedkavoosi ${ }^{1}$ and I. Sevostianov ${ }^{2}$ \\ ${ }^{1}$ Department of Engineering, University of Tennessee at Martin, Martin, TN 38238 USA \\ ${ }^{2}$ Department of Mechanical and Aerospace Engineering, New Mexico State University, P.O. Box 30001, \\ Las Cruces, NM 88003, USA
}

Received: October 06, 2019

\begin{abstract}
In this review we discuss mechanical properties of dentin in relation to its microstructure. Dentin is a rather complex anisotropic material with hierarchical structure consisting of collagen fibers and hydroxyapatite particles at the lower level. Different concentrations of hydroxyapatite in this tissue correspond to peritubular and intertubular dentins. At the next, microscopic level dentin can be represented as intertubular dentin matrix containing parallel cylindrical holes (the tubules) surrounded by layers of peritubular dentin. Generally, dentin shows viscoelastic behavior; however, its reaction on fast loading can be described in the framework of elasticity. We review the state-of-the-art of dentin experimental characterization and methods of micromechanical modeling of its overall elastic and viscoelastic properties.
\end{abstract}

\section{INTRODUCTION}

Dentin is a collagen and calcium phosphate-based yellowish-white bio-composite that forms the bulk of mammalian teeth. It is closely related to bone. Dentin is partially covered by a thin, stiff and brittle layer of enamel in areas of the tooth crown through dentino-enamel junction (DEJ). In the root part of the tooth, dentin is covered by cementum (50-200 $\mu \mathrm{m}$ thick), which has a role to attach the tooth to the jawbone (Fig. 1). Blood vessels and nerve bundles enter the pulp chamber through canals within the roots (Fig. 2). This allows fully grown teeth to react or respond to external stimuli by sensation or tissue formation.

Dentin in human teeth is the most extensively researched type of tissue. Much is now known about its development and characteristics in the last century. However, there are many open aspects of dentin behavior and characteristics remain unknown in both mechanical and biological fields of research.

\section{COMPOSITION AND MICROSTRUCTURE OF DENTIN}

Dentin is a composite material with composition and microstructure varying along the teeth [1-3]. Comparing to enamel, dentin is less mineralized, tougher, more elastic, has fewer inorganic components and higher porosity $[4,5]$. Verdelis et al. [6] showed the change in mineral properties of both crawn and root dentin are not a linear and has some different developmental mechanisms. The dentino-enamel junction (DEJ) as the interface between dentin and enamel is less mineralized and has more collagen compare to dentin which makes it a perfect link to transfer applied loads from masticatory and impact from enamel to dentin and to protect the tooth from propagating cracks in enamel into dentin [7]. Dentin at the cementum dentin junction (CDJ) has lower mechanical properties and contains less minerals and more organic materials. A softer and wider cementum dentin junction (CDJ) can aid in cushioning and lubricating as well as allowing the passage of nutrients between cementum and dentin. The overall function of the cementum dentin junction (CDJ) could aid absorption and distribution of loads from dentin to cementum and the bone [8]. All these characteristics make dentin a foundation for teeth to support enamel and compensate for its brittleness and the whole functionality of teeth.

Dentin is a sensitive tissue, and more important, it is capable of repair, because odontoblasts or cells in the pulp that can be stimulated to deposit more dentin if

Corresponding author: I. Sevostianov, e-mail: igor@nmsu.edu

(C) ITMO University, 2019 
Table 1. Physical properties of dentin components (revised version of Table A3.1 from J. Black and G. Hastings, Handbook of biomaterial properties. Springer Science \& Business Media, 2013).

\begin{tabular}{llll}
\hline Constituents & Density & Weight Percentage in Dentin & Volume Percentage in Dentin \\
\hline Mineral & $3000 \mathrm{~kg} / \mathrm{m}^{3}$ & 70 & 50 \\
Organic & $1400 \mathrm{~kg} / \mathrm{m}^{3}$ & 20 & 30 \\
Water & $1000 \mathrm{~kg} / \mathrm{m}^{3}$ & 10 & 20 \\
\hline
\end{tabular}

needed [9]. A material that can completely take the place of human teeth regarding biological and mechanical properties has not yet been found. Human teeth have a more complicated structure, better mechanical properties and better biocompatibility than all dental restorative materials, including synthetic resin materials, ceramic materials and dental alloys [10].

Dentin contains approximately $70 \mathrm{wt} . \%$ of inorganic material, $18 \mathrm{wt} . \%$ of organic matrix and $12 \mathrm{wt} . \%$ of water [11] (Table 1). It is composed of a hydrated organic matrix consisting mostly of type I collagen (approximately

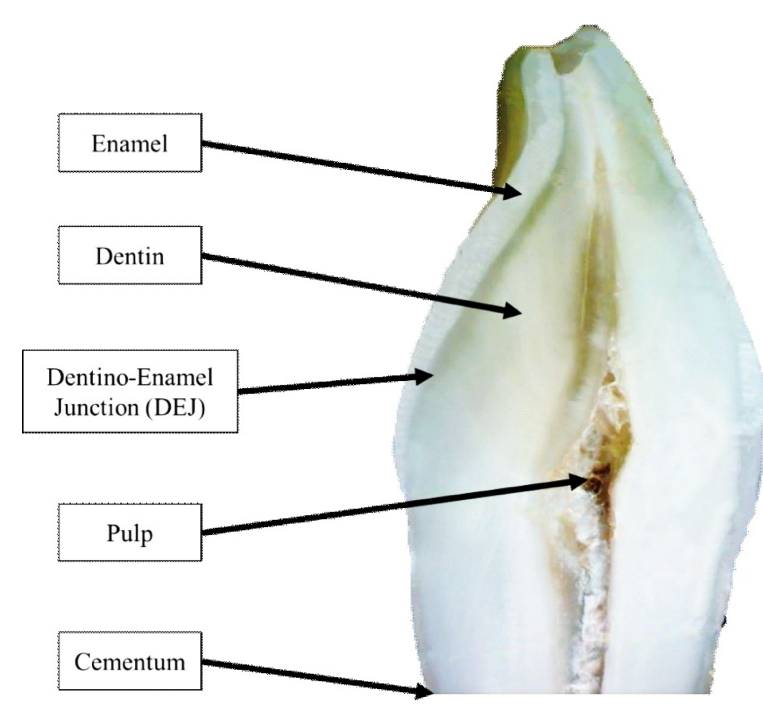

Fig. 1. Tooth anatomy adapted from Peter Fratzl, "Collagen," (Springer, 2008).

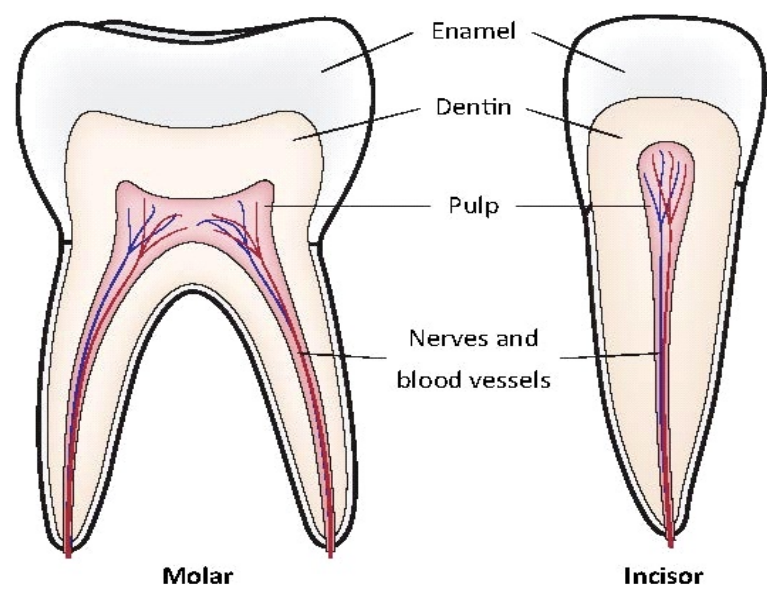

Fig. 2. Microstructure of molar and incisor teeth.
Table 2. Chemical constitutions of human dentin (revised version of Table A3.2 from J. Black and G. Hastings, Handbook of biomaterial properties. Springer Science \& Business Media, 2013).

\begin{tabular}{ll}
\hline Element Name & $\begin{array}{l}\text { Range of Weight } \\
\text { Percentage in Dentin }\end{array}$ \\
\hline $\mathrm{Ca}$ & $27.3 \pm 0.2$ \\
$\mathrm{P}$ & $13.5 \pm 0.1$ \\
$\mathrm{Na}$ & $0.68 \pm 0.005$ \\
$\mathrm{C}$ & $0.61 \pm 0.013$ \\
$\mathrm{~K}$ & $0.02 \pm 0.001$ \\
$\mathrm{Mg}$ & $0.75 \pm 0.012$ \\
$\mathrm{CO}$ & 4.6 \\
\hline
\end{tabular}

$90 \%$ ) in the form of a highly textured fibrous matrix mesh and an inorganic reinforcing phase of carbonated apatite mineral - hydroxyapatite (HAp) [12,13]. Small amounts of other types of collagen, IV, V, and VI, have also been found in dentin [14]. Other organic components of dentin are mostly non-collagenous proteins. The organic matrix in dentin made of collagen fibrils $(\sim 10 \mu \mathrm{m}$ such as the ones found in bone). The main role of the collagen fibril matrix is to control the deposition and orientation of the HAp mineral crystals [15-17]. Kinney et al. [18] used the technique of small angle $X$ ray scattering (SAXS) to determine the orientation of collagen fibers in dentin matrix. Closer to the pulp and in the plane of mineralization, the collagen fibrils were oriented approximately isotopically and with increasing distance from the pulp the fibril orientation became more anisotropic and reached to max anisotropy in the dentin approximately $1.3 \mathrm{~mm}$ from pulp. The HAp mineral crystals in dentin like the ones in bone, is $\mathrm{CaO}_{1}(\mathrm{OH})_{2}\left(\mathrm{PO}_{4}\right)_{6}$. The crystals are plate like $2-4 \mathrm{~nm}$ thick, $30 \mathrm{~nm}$ wide, and up to $100 \mathrm{~nm}$ long [16]. The mineral crystals in dentin are associated with the collagenous matrix, that they are largely arranged with their c-axes parallel to the collagen fibers, randomly oriented in the matrix [15]. Table 2 gives the chemical constitutions of human dentin.

Dentin is formed by tall columnar cells located at the edge of the dental pulp, odontoblasts [19]. In the process of dentin mineralization, the odontoblasts start from 


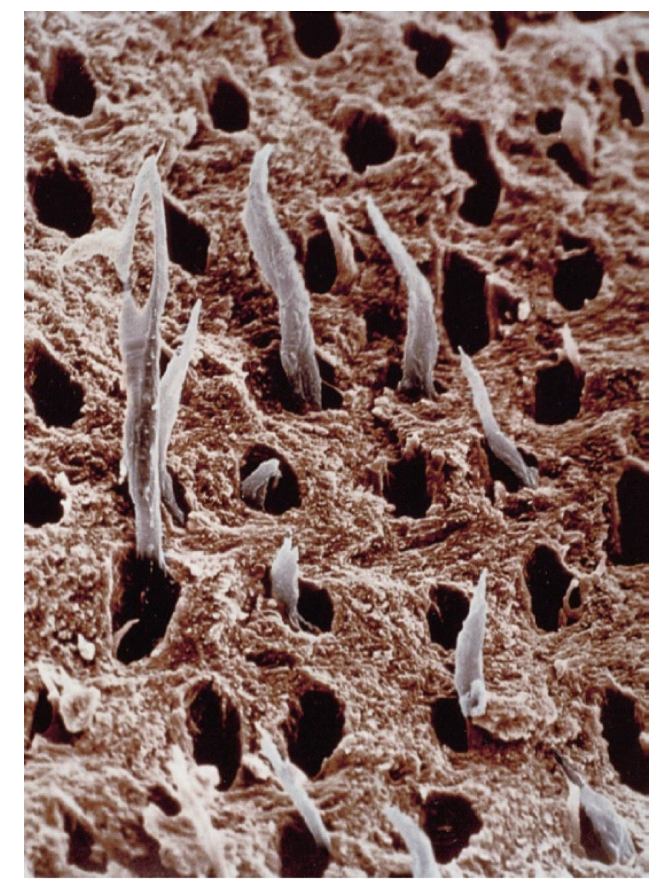

Fig. 3. Scanning Electron Micrograph of fractured dentin near the pulp. Odontoblasts' terminal ends inside the tubules can be seen (Adapted from G. Goracci, G. Mori, and M. Baldi, "Terminal end of the human odontoblast process: a study using SEM and confocal microscopy.," Clin. Oral Investig., vol. 3, no. 3, pp. 126132, 1999).

the outer surface and go backward to the pulp region (Fig. 3). After mineralizing, Odontoblasts will keep having the cell processes. These processes extend far out into dentin surrounding the pulp, radiating outward through long and narrow tubules that they created. These parallel tubules are mostly circular cross-section
- that oriented outward from the pulp to the dentinoenamel junction (DEJ) in coronal dentin, and from the pulp canal to the cementum in the root [12] (Fig.4). At dentino-enamel junction (DEJ) and the surfaces touching the dental pulp the tubules are approximately $0.6 \mu \mathrm{m}$ and $3 \mu \mathrm{m}$ in diameter, respectively. Closer to the dental pulp, the tubules are wider and packed closer to each other [2]. The Scanning Electron Microscopic (SEM) investigations of human dentinal tubules have demonstrated approximately 45,000 tubules per square millimeter at the pulp, 29,500 tubules per square millimeter in the middle dentine, and 20,000 tubules per square millimeter peripherally [2]. Moreover, the chemical components of dentin also change along the tubules [20]. Tubules approximately occupy $10 \%$ of the total dentin volume [21]. Near the pulp, the tubules converge and their internal diameters double. A way from the pulp, the tubules traverse the entire dentin thickness, thus ending adjacent to cementum at the dentino-cemental junction (DCJ) in the root, or near the dentino-enamel junction (DEJ) in the crown. Near these junctions, each tubule branches and terminates, although on occasion, they may penetrate into the adjacent tissue [22]. Collagen fibers solid framework is arranged in the planes perpendicular to the tubules [23] (Fig. 5). These tubules are lined by a highly mineralized cylinders, composed largely of apatite called peritubular dentin. Peritubular dentin is roughly $0.5-1 \mu \mathrm{m}$ thick in a normal human dentin [12]. The volume fraction of mineral content in peritubular dentin is about $90 \%$ [4]. The peritubular dentin is thicker near dentino-enamel junction (DEJ) and much thinner near the pulp [24]. The tubules and peritubular dentin separated by intertubular dentin that consists of a less mineralized collagen matrix. The organic content of in-

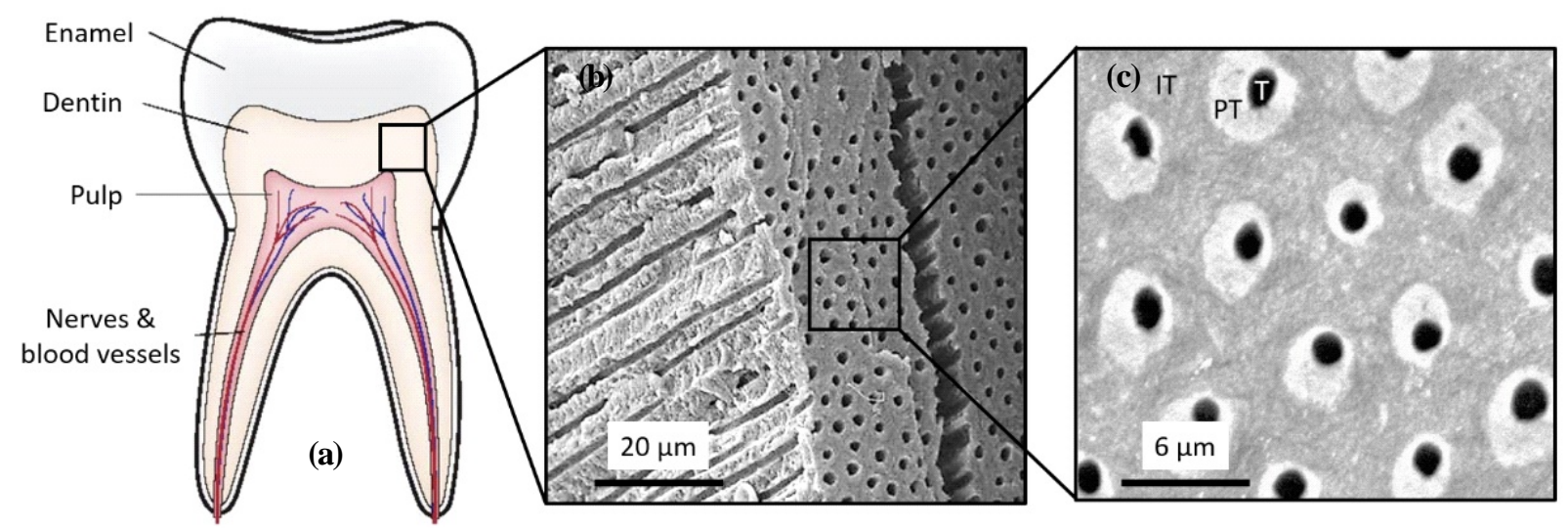

Fig. 4. (a) Microstructure of molar tooth and dentin (adapted from [115].), (b) SEM image showing the microstructure of dentin (adapted from https://www.odont.uio.no/studier/ressurser/histologi/snitt/snitt.php?katalog=052\&size $=0 \&$ info $=)$, (c) microstructure of dentin at higher resolution: tubule $(\mathrm{T})$, peritubular dentin $(\mathrm{PT})$, and intertubular dentin (IT) are labeled in the picture (adapted from P. Zaslansky, S. Zabler, and P. Fratzl, "3D variations in human crown dentin tubule orientation: A phase-contrast microtomography study,” Dent. Mater., vol. 26, no. 1, pp. 1-10, 2010). 


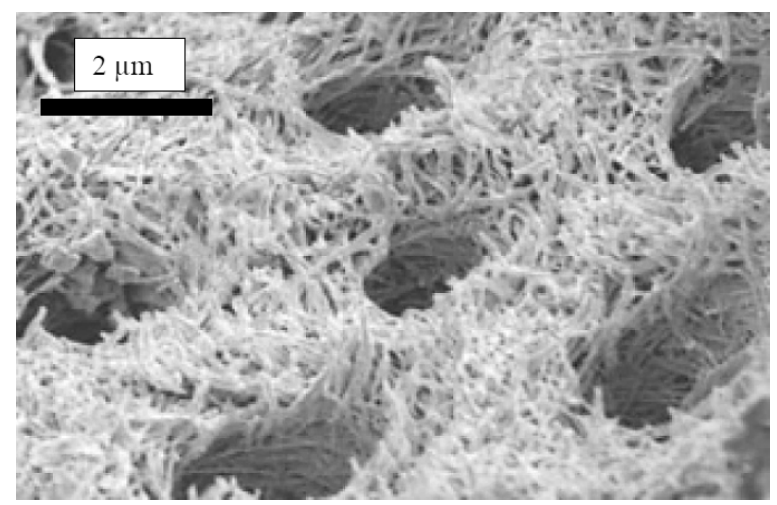

Fig. 5. Scanning electron image of collagen seen in a freeze-dried etched dentin surface (courtesy of Dr Jorge Perdigăo) adapted from P. Vallittu, Non-metallic biomaterials for tooth repair and replacement, Elsevier, 2012.

tertubular dentin is approximately three times of those in peritubular dentin [25]. Previously, many research groups assumed that peritubular dentin has a small volume fraction of the total dentin matrix [26]. The study of peritubular dentin distribution in human coronal dentin using micro-radiography shows that peritubular dentin has a relatively large faction and it can reach to the same volume fraction of intertubular dentin in some parts of coronal dentin [27]. The effect of age and location reigns within inner, middle and outer part of dentin on its microstructure and chemical composition was studied by Montoya et al. [28] using electron and optical microscopy and the mineral-to-collagen ratio in these three regions was estimated using Raman spectroscopy. They showed tubule density, tubule diameter and peritubular dentin thickness change significantly with depth; however, the effects of aging on tubule density and diameter is minimal, and the mineral content increase with aging (Table 3).

\section{ELASTIC PROPERTIES OF DENTIN}

\subsection{Experimental measurements}

The mechanical properties of dentin have been studied for more than a century. To the best of our knowledge, the first systematic experimental study of mechanical properties of dentin was performed by Black [29] who, in particular, showed that location and orientation of the tubules of the test specimens do not significantly affect the overall properties. Craig and Peyton [30] studied the effects of dentin tubules and did not find any connection between the orientations of tubules and the dentin elastic properties. This result was later argued in works of Peyton et al. [31] and Stanford et al. [32]. Because the peritubular dentin is highly mineralized, it had long been suspected that dentin had a higher elastic modulus in the direction of the tubules. Recent studies showed the elastic properties of dentin are determined by the mineralized collagen fibers in intertubular dentin, therefore it is stiffest in an orientation perpendicular to the axes of the tubules [12,23]. Renson and Braden [33] tested the anisotropy of dentin by testing the fracture properties, shear modulus and the Poisson's ratio of dentin experimentally. They showed that the existence of collagenous fibers in intertubular dentin will cancel out the dentin tubule transverse isotropy effect and dentin in an isotropic material. Rasmussen et al. [34] showed that dentin can fracture easier in the direction

Table 3. Comparison of tubule density, tubule diameter, peritubular dentin diameter, and distribution of mineral-tocollagen ratio of young and old coronal dentin as a function of depth (adapted from C. Montoya, S. Arangosantander, A. Peláez-vargas, D. Arola, and E. A. Ossa, "Archives of Oral Biology Effect of aging on the microstructure, hardness and chemical composition of dentin," Arch. Oral Biol., vol. 60, no. 12, pp. 1811-1820, 2015).

\begin{tabular}{llll}
\hline & & Young \\
& & $(18$ and 25 years old $)$ & $\begin{array}{l}\text { Old } \\
\text { (47 and 65 years old) }\end{array}$ \\
\hline Tubules density & Outer & 11400 & 12300 \\
$\left(\right.$ Tubules $\left./ \mathrm{mm}^{2}\right)$ & Middle & 10300 & 9600 \\
& Inner & 8050 & 9200 \\
Tubule diameter & Outer & 1.36 & 1.24 \\
$(\mu \mathrm{m})$ & Middle & 1.63 & 1.65 \\
& Inner & 1.84 & 1.81 \\
Peritubular dentin & Outer & 2.80 & 2.99 \\
diameter $(\mu \mathrm{m})$ & Middle & 3.22 & 3.09 \\
& Inner & 3.50 & 3.32 \\
Mineral to & Outer & 0.74 & 1.33 \\
collagen ratio & Middle & 0.72 & 1.0 \\
& Inner & 0.66 & 0.67 \\
\hline
\end{tabular}




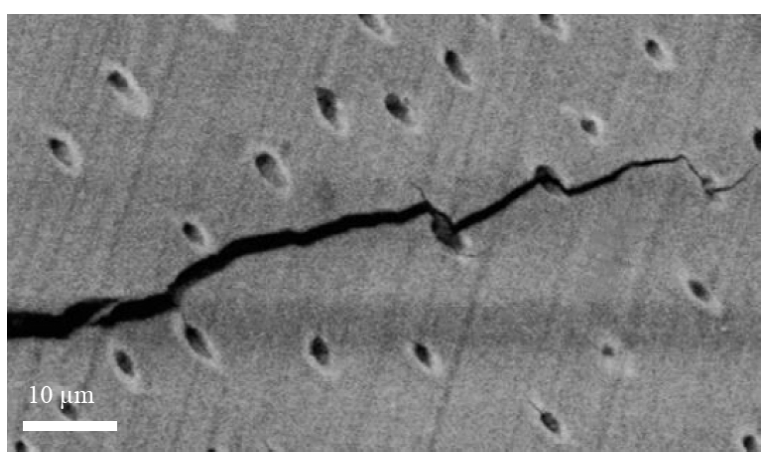

Fig. 6. Micrograph of a propagating crack in moist young dentin (Adapted from J. Koester, J. W. Ager, and R. O. Ritchie, "The effect of aging on crack-growth resistance and toughening mechanisms in human dentin," Biomaterials, vol. 29, no. 10, pp. 1318-1328, 2008).

perpendicular to the dentin tubules than in the parallel direction which supports that dentin demonstrates anisotropic (transversely isotropic) properties. Pashley et al. [35] showed the inverse correlation between dentin microhardness and tubular density in normal human permanent teeth. Watanabe et al. [36] showed that dentin shear strength is dependent on dentin tubule orientation. Lertchirakarn et al. [37] experimentally evaluated the effects of tubules and collagen fibril orientation on the ultimate tensile strength of dentin. Scanning Electron Microscope (SEM) images of fractured surfaces confirms that the fracture patterns are affected by the microstructure. In a later work, the effects of tubule orientation and density on ultimate tensile strength of human dentin were tested by Carvalho et al. [38] using uniaxial testing machine and SEM. The results showed dentin has a higher ultimate tensile strength in the direction perpendicular to the tubule orientation than in the parallel direction to the tubule orientation, they concluded that the tubule density does not affect the ultimate tensile strength of dentin significantly. Inoue et al. [39] applied tensile test on dentin samples in distilled water at a temperature of $37^{\circ} \mathrm{C}$ to calculate the tensile strengths of dentin and showed it is significantly greater parallel to the tubules than those of the perpendicular direction. They also showed the tensile strengths of root dentin were significantly greater than those of the coronal dentin. Moreover, in the root dentin, the tensile strengths of the perpendicular to dentinal tubules differ with respect to tensile forces. Their results suggested that tensile strength of dentin behaves differently with respect to the location and orientation of dentinal tubules in the tooth. Arola et al. [40] analyzed the fatigue and fracture properties of bovine dentin experimental. They applied the Paris law to evaluate the fatigue crack growth rate of dentin as a function of the tubule orientation. A larger fatigue crack growth rate was reported for crack propagation occurring perpendicular to the dentin tubules. Fig. 6 shows a SEM image of a propagating crack in moist young dentin. The effects of tubule orientation and dentin location on the micro-tensile strength of bovine root dentin was evaluated by Liu et al. [41] in three different directions, parallel, perpendicular, and oblique direction (between 0 and 90 degrees to the tubules direction) with respect to the tubules' orientation. The oblique direction was reported more than two times higher than the parallel direction and perpendicular direction was the lowest value. Therefore, they showed in the tensile stress testing of the root dentin, the oblique orientation was harder to fracture compare to parallel or perpendicular orientations. Iwamoto and Ruse [42] studied the fracture toughness of human dentin and evaluated its dependence to the tubules' orientation. The fracture toughness for the orientations parallel to the dentinal tubules was significantly higher compared to perpendicular direction, which shows a significant anisotropy of dentin with respect to its fracture toughness. Zheng et al. [43] studied the differences in the friction and wear behavior of human dentin against titanium and measured the micro-indentation hardness of worn teeth specimens and showed anisotropic friction and wear behavior of dentin regarding the dentinal tubule orientations. Arola and Rouland [44] studied the rate of fatigue crack growth in dentin under mode I cyclic loading with respect to tubules orientation. They showed the average fatigue crack growth exponent parallel to the dentin tubules was significantly larger than that for the direction perpendicular to the tubules. Kinney et al. [45] applied resonant ultrasound spectroscopy (RUS) to measure the elastic constants of hydrated human crawn dentin and showed dentin has a small hexagonal anisotropy and it is stiffer in the direction perpendicular to the axis of the tubules. Wang [46] applied strain concentration tests and impression-induced damage tests on coronal and root dentin and demonstrated that dentin anisotropy in terms of fracture properties and both location and orientation affect tooth failure behavior. Arola and Reprogel [47] studied the effects of tubule orientation on the strength of human dentin under static and cyclic loading for parallel and perpendicular directions to the tubules' orientation. They confirmed the fatigue crack growth resistance of dentin is lowest for perpendicular direction to the tubules. Moreover, there was a decrease in both the flexure strength and energy to fracture of dentin with increasing tubule density. Yan et al. [48] investigated the fracture toughness of dentin using elastic-plastic fracture mechanics and showed fracture toughness of anti-plane parallel specimens is significantly greater than that of in-plane parallel specimens. Inoue et al. [49] studied the tensile strength of coronal dentin as a function of loca- 
tion, parallel and perpendicular to the tubule's direction. They showed the anisotropy behavior of tensile strength in coronal dentin governs by the collagen fibrils (perpendicular to the tubules direction). They also showed type of tooth will affect the microstructure and hence its fractures behavior. Ivancik et al. [50] evaluated the fatigue crack resistance of human coronal dentin and showed dentin exhibits the lowest resistance to fatigue crack growth perpendicular to the tubules. Wang et al. [51] developed a mechanical model to simulate peritubular reinforcement effect of porous dentine tubules and showed the overall stiffness of dentine increases with thickness of the tubules.

Dentin characteristics are anisotropic regarding the location in the tooth and orientations of dentinal tubules. For decades, many researchers showed that the mechanical properties of dentin vary along the tooth. Meredith et al. [52] applied micro indentation on human dentin samples and measured the hardness and Young's modulus as a function of location. Wang and Weiner [53] mapped the in-plane strain distributions in human dentin under compression and showed the strains in dentin vary from dentino-enamel junction (DEJ) to pulp. $\mathrm{Xu}$ et al. [54] performed indentation studies to understand the microfracture and deformation and the microcrack-microstructure interactions of tooth. In this study, they measured hardness, fracture toughness, elastic modulus, and energy absorbed of dentin during indentation. Fong et al. [55] investigated the Nano-hardness and elastic modulus of human incisor teeth across the dentino-enamel junction (DEJ). They showed that, over a length scale of about $20 \mathrm{~mm}$, there were decreasing trends in both hardness and elastic modulus across the dentino-enamel junction (DEJ) zone profiling from enamel to dentin. Tesch et al. [56] analyzed the change in mechanical and structural properties of dentin in an area between 0 and $1.5 \mathrm{~mm}$ below the dentino-enamel junction (DEJ) as crown part of dentin and showed its properties optimized for its mechanical function. They showed the mineral content of dentin decreases and the thickness of mineral crystals increases towards the dentino-enamel junction (DEJ). On the other hand, hardness and elastic modulus both decreased towards the dentino-enamel junction (DEJ). Staninec et al. [57] studied the change in the ultimate tensile strength of dentin with location in the tooth. They observed the ultimate tensile strength was significantly lower in inner dentin than in outer dentin which can be because of preexisting defects in the dentin. Inoue et al. [58] showed the tensile strengths of the root dentin were significantly greater than those of the coronal dentin. However, in the radicular dentin, the tensile strengths of the perpendicular to the tubules differ with respect to tensile forces. Nalla et al. [59] experimentally studied the fracture behavior of human dentin to examine the character of the deformation, local fracture mechanisms and the role of the principal microstructural features in influencing the process of crack initiation and growth. Inoue et al. [58] calculated the ultimate tensile strength of dentin experimentally to evaluate the effect of dentin depth and showed superficial dentin showed a significantly higher ultimate tensile strength than deep dentin. The tubule density of superficial dentin was significantly lower than that of middle and deep dentin. Nalla et al. [23] studied the effect of pre-crack on the fracture toughness of human dentin experimentally. Fuentes et al [59] studied the microhardness of superficial and deep dentin and showed dentin microhardness is not influenced by the loads. Mannocci et al. [60] found the ultimate tensile strength of lower root dentin is significantly higher than those of closer to coronal dentin. They also showed that the number of dentinal tubules of the samples from the middle part of the root is significantly higher than that of samples from the lower part. Cohen [61] applied an AFM-based experiments on crown dentin and showed a gradient of mechanical properties across the peritubular dentin and through the peritubular dentin - intertubular dentin junction. They indicated that the peritubular dentin undergoes a graded change in hardness/modulus across its cross section and there is an inverse relation between the stiffness and piezo-response, reflecting the collagen-mineral content ratio changes near to and across the peritubular dentin intertubular dentin junction. Inoue et al. [62] compared the hardness and Young's modulus of the coronal and root intertubular dentin using nanoindentation tests, at two locations per tooth and showed that the hardness and Young's modulus of coronal intertubular dentin were greater than those of root intertubular dentin. Ivancik et al. [63] characterized the fatigue crack growth resistance of dentin as a function of distance from the dentinoenamel junction (DEJ). They showed an increase in the average fatigue crack growth rate with location as a result of tubule density. Ryou [64] evaluated the mechanical behavior of coronal dentin at different depths from the dentino-enamel junction (DEJ) experimentally and showed the deep dentin presents lower elastic modulus, strength, critical strain, and energy to fracture compare to those of the superficial dentin. Fan [65] used resonant ultrasound spectroscopy (RUS) to evaluate dentin mechanical properties.

Viidik [66] gave a review of the mechanical properties of collagenous tissue (including dentin) and their relation to material morphology. Katz [67] evaluated the elastic properties of hard biological tissues by focusing on their microscopic level. Lehman [68] evaluated the tensile strength of dentin and showed the tensile strength of human dentin is much below its compressive 
strength. Bo and Quanshui [69] presented a varying transverse isotropic stress-strain relation of dentin. Marshall et al. [70] used atomic force microscopy (AFM) to determine the Young's modulus and hardness of intertubular and peritubular dentin in and below carious dentin. They observed that intertubular dentin is the major factor in determining the mechanical properties of dentin when considered as a composite structure. Kinney et al. [71] provided a detailed review of the experimental results on the mechanical properties of human dentin obtained in the second half of XX century. The authors briefly discussed the composition and microstructure of dentin and then summarized results on its elastic properties, hardness, strength, fracture toughness, and fatigue. Lee et al. [72] analyzed the effects of organic tissue removal of dentin using $\mathrm{NaOCl}$ (sodium hypochlorite) on its morphological changes and punch shear strength by applying low vacuum wet scanning electron microscope (Wet-SEM) and punch shear apparatus. After removing the organic tissue, the structure of intertubular and peritubular dentin was compromised, and many interconnected cracks were formed. Yan at al. [73] applied quantitative fractography to study the fracture pattern and fracture toughness of human crown dentin and showed human dentin has a fracture surface similar to brittle materials.

There are many natural changes that occur to human teeth with aging, including its physical and chemical structure. This is important from the perspective of understanding the fundamental properties of dentin and its microstructure related to aging. Tonami and Takahashi [74] applied tensile tests and tensile fatigue tests in $37^{\circ} \mathrm{C}$ water with the bovine dentin specimens of young and old age groups. They showed that the tensile fatigue strength and tensile strength both decrease with aging. Arola and Reprogel [75] tested the effects of age on the fatigue properties of human dentin and showed that the fatigue strength of dentin, maximum flexure strength, and energy to fracture of dentin decrease with age. Koester et al. [76] applied a crack-growth experiments in situ to evaluate fracture toughness of dentin from crack growth resistance curves of human dentin and its degradation with aging. They observed in the younger dentin up to $4 \%$ of the tubules filled with apatite; the aged dentin up to $100 \%$ filled tubules. Aging in dentin results in the filling of tubules with carbonated apatite, which can diminish the crack-growth toughness by a factor of two but has little effects on the crackinitiation fracture toughness.

Nazari et al. [77] compared the crack growth resistance of human coronal dentin with age and showed there is a significant reduction in both the initiation $(K o)$ and plateau $(K \mathrm{p})$ components of toughness with patient age. Microstructural changes with aging decrease the capacity for near-tip inelastic deformation and microcracking of the tubules, which in turn suppressed the formation of unbroken ligaments and the degree of extrinsic toughening. Ivancik et al. [50] tested the fatigue crack resistance of human coronal dentin through application of mode I cyclic loading to identify the degree of degradation that arises with aging and the dependency on tubule orientation and observed regardless of tubule orientation, aging cause significant reduction in the resistance to the initiation of fatigue crack growth, as well as a significant increase in the rate of incremental extension. Regardless of age, coronal dentin exhibits the lowest resistance to fatigue crack growth perpendicular to the tubules. Ryou et al. [78] performed an experimental evaluation of human coronal dentin using nanoscopic Dynamic Mechanical Analysis (nanoDMA) and saw no significant differences in the storage modulus or complex modulus between the two age groups (18-25 versus 54-83 years) for either the intertubular or peritubular tissue. However, they observed significant differences in the dampening behavior between the young and old dentin. Scanning based nanoDMA showed that the tubules of old dentin exhibit a gradient in elastic behavior, with decrease in elastic modulus from the cuff to the center of tubules filled with newly deposited mineral. Montoya et al. [28] studied the effects of aging on the microstructure, chemical composition and hardness of human coronal dentin and

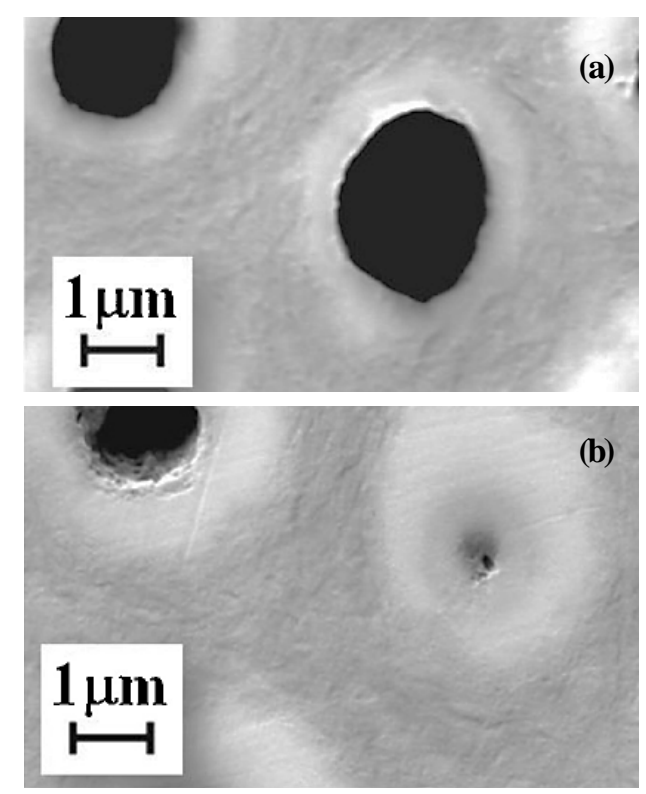

Fig. 7. Micrographs of dentin tubules of young (up, 18 years old) and old (down, 65 years old) donors (Adapted from C. Montoya, S. Arango-santander, A. Peláez-vargas, D. Arola, and E. A. Ossa, "Archives of Oral Biology Effect of aging on the microstructure, hardness and chemical composition of dentin," Arch. Oral Biol., vol. 60, no. 12, pp. 1811-1820, 2015). 
showed there was a significant increase in the occlusion ratio of the tubules with age. In old patients, an increase in mineral content was found in outer coronal dentin because of tubule occlusion. However, there was no difference in tubule density and diameter of the tubules with aging. Fig. 7 shows micrographs of dentinal tubules of young and old donors.

Dentin is a natural bio-composite with mineralized collagen matrix. There is a large difference in modulus between the mineral and organic phases of dentin. Sano et al. [79] tested the hypothesis that demineralized collagen matrix slightly contributes to the tensile strength of fine dentin and concluded that it contributes approximately $30 \%$ of the ultimate tensile strength of mineralized dentin. Balooch et al. [80] used atomic force microscopy on individual collagen fibrils to study structural and mechanical changes during acid etching. The Nanoindentation showed a significant decrease in elastic modulus during acid etching of individual collagen fibrils. They showed the intrafibrillar mineral is a major contributor to the strength of mineralized tissues and any attempt to remineralize such tissues must provide for crystallization in their gap zones.

Bertassoni et al. [81] evaluate the common remineralization methodologies of dentin and showed the recovery of dentin mechanical properties should be the concern aspect in the process of remineralization. Bertassoni et al. [81] evaluated the effectiveness of remineralization of dentin and with the focus on the biomechanical perspectives. Bertassoni et al. [82] studied the surface structural and mechanical changes leading to remineralization of dentin. They showed that by continuously delivering calcium and phosphate ions to the demineralized dentin matrix, the mechanical properties will be recovered in a good extend. Bertassoni et al. [83] used Nanoindentation to study the effect of remineralization and mechanical recovery of hydrated dentin in water. Mechanical recovery appeared to initially obey a heterogeneous pattern; however, with time, it moves towards a more homogenous matrix. Chen et al. [84] performed a nanoindentation experiments to determine the mechanical behavior of the remineralized dentin and showed the mechanical properties of the remineralized dentin is related to the mineral density, the nanoarchitecture and the crystallinity of the dentin minerals. Fig. 8 shows a SEM image of a cross-sectional view of sound dentin and completely demineralized dentin.

Balooch et al. [85] used an atomic force microscope to measure the mechanical properties of demineralized human dentin under three conditions: in water, in air after desiccation, and in water after rehydration. The experiments showed that contribution of collagen fibers

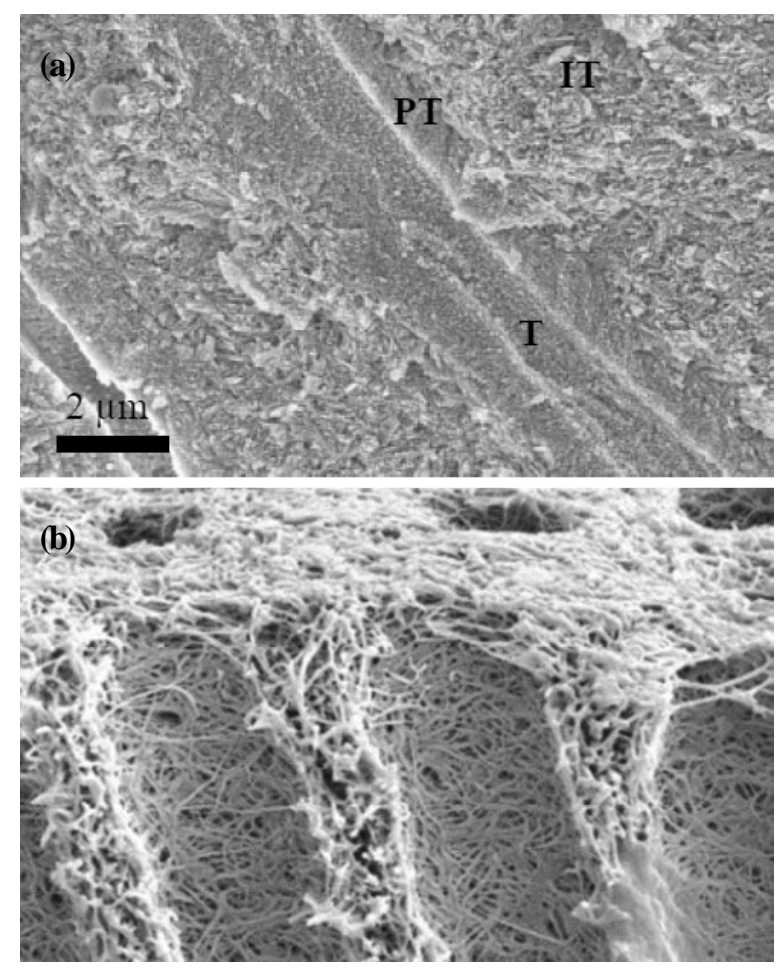

Fig. 8. Scanning electron microscopy (SEM) showing a cross-sectional view of sound dentin (up) and completely demineralized dentin (dawn). The structure of the tubules (T), peritubular dentin (PT) and well mineralized intertubular dentin (IT) of sound dentin can be observed. All the minerals on the surfaces and interiors of the dentin slices were dissolved and had disappeared (Adapted from X. Wu, M. L. Mei, Q. Li, C. Y. Cao, J. Chen, and R. Xia, "A Direct Electric Field-Aided Biomimetic Mineralization System for Inducing the Remineralization of Dentin Collagen Matrix," pp. 78897899, 2015).

into elastic stiffness of dentin is negligible, although collagen is a significant contributor to dentin strength and toughness. Huang et al. [86] conducted tensile, compression, and impact tests to see whether significant differences exist between the mechanical properties of human dentin after different treatments as wet, air dried, dehydrated, and rehydrated. They showed that the dehydration of dentin increases the elastic properties including Young's modulus and the ultimate strength in both compression and tension. Jameson et al. [87] investigated the effect of dehydration and rehydration on the brittleness and toughness of human dentine. They observed the stress at fracture in bending or tensile tests did not change significantly between hydrated, dehydrated or rehydrated dentin. However, strain at fracture and fracture energy were significantly greater for hydrated and rehydrated than for dehydrated dentine. Dehydration of human dentine resulted in decreased 
strain at fracture and demonstrated a brittle behavior. Kinney et al. [88] used atomic-force microscope to measure the hardness of fully hydrated peritubular and intertubular dentine at two locations within sound human molars. Arola and Zheng [89] applied an experimental investigation on the dynamic fatigue response of coronal dentin to examine the influence of stress rate on the strength and energy to fracture in the fully hydrated and dehydrated conditions at stress rates ranging from 0.01 to $100 \mathrm{MPa} / \mathrm{s}$. The hydrated dentin showed that the flexure strength, energy to fracture, and flexure modulus all increased with increasing stress rate. The elastic modulus and strength of the dehydrated dentin decreased with increasing stress rate. According to their results, restorative conditions that cause development of static stresses within the tooth could promote a decrease in the damage tolerance of dentin. Ziskind et al. [90] evaluated the local Young modulus of dry dentin as a hierarchical composite by nanoindentation.

Dentin bonding properties and microstructure as of any other biomaterial is sensitive to temperature change. Rasmussen and Patchin [91] applied the SEM fractography and work-of-fracture techniques to investigate the fracture properties of human enamel and dentin as a function of the temperature and showed little change in fracture properties with respect to temperatures. Watts el al. [92] evaluated the effect of temperature on compressive stress/strain behavior of human dentin. They showed the temperature coefficient of the modulus has the same behavior as cortical bone. Proportional limit, compressive strength, and resilience are having a linear decrease with increasing temperature. They also showed that the mechanical failure of specimens mainly happens approximately 45 degrees to the axial load direction, which is along the lines for maximum shear stresses. Hayashi et al. [93] applied heat treatment with tensile test on dentin and observed the flexural strength of type I collagen, the major organic component of human dentin, increases with heat. The flexural and micro-tensile strengths of dentin in the parallel specimens were approximately 2.2 times greater after being heated between $110^{\circ} \mathrm{C}$ and $140{ }^{\circ} \mathrm{C}$ for 1 hour. However, the Young's moduli did not change regardless of dehydration or heating. Hayashi et al. [94] investigated the micro-structure of human dentin and chemical changes in dentin collagen by heating at $140{ }^{\circ} \mathrm{C}$ using nanoindentation and X-ray diffraction. They showed the micro-hardness of intertubular dentin increased after heating at $140{ }^{\circ} \mathrm{C}$ to 1.8 times more than unheated dentin; on the other hand, peritubular dentin was unchanged. Results of X-ray diffraction showed that the lateral packing of collagen molecules shrank from about $23 \%$ after heating, but the shrinkage reversed to the original after rehydration without any chemical changes.

\subsection{Micromechanical modeling}

The commonly used analytical model of dentin represents it as a set of parallel cylindrical pores (tubules) in an isotropic homogeneous matrix. This model, however, is over simplistic. First, the matrix (dense tissue) is a combination of two anisotropic phases - collagen fibers and hydroxyapatite platelet-like crystals. Second, all the tubules are surrounded by peritubular dentin with higher concentration of hydroxyapatite than in in the intertubular dentin. Detailed description of dentin microstructure was provided by [22]. Bo and Quanshui [69] presented a varying transverse isotropic stress-strain relation of dentin. Kinney et al. [95] introduced a generalized self-consistent model of cylindrical inclusions in a homogeneous and isotropic matrix phase and evaluated the effects of tubule orientation on the elastic properties of dentin. Kinney et al. [95] presented a micromechanical model to study the effect of tubules orientation on the mechanical properties of dentine. Qin and Swain [96] proposed a micromechanics model where tubules are represented as circular hollow cylinders, filled with liquid or gas phase, surrounded by two circular cylindrical shells corresponding to peritubular and intertubular dentin, assuming however that both of these shells are isotropic. Wang and Qin [97] drove a generalized self-consistent method and the strain energy principle to evaluate effective elastic moduli of human dentine assuming the dense tissue is isotropic. Wang et al. [98] calculated viscoelastic properties of dentin modeling it as a transversely-isotropic viscoelastic material with known properties containing parallel cylindrical pores. Bar-on and Wagner [99] proposed a multiscale mechanical model for the tooth enamel and dentin and estimated their effective moduli. They used the staggered microstructure approach to evaluate the properties of intertubular dentin. The HAp platelets and the collagen matrix are considered as isotropic. Sui et al. [16] discussed the relationship between the nanoscale crystal distribution and macroscopic mechanical elastic response of human dentine using a combined in situ synchrotron SAXS/ WAXS technique. They proposed a multiscale Eshelby inclusion model that considers the two-level hierarchical structure of human dentin. In their model they considered the dentin matrix and HAp crystals as isotropic materials. Yoon [100] characterized the elastic constants of dentin by developing effective composite moduli, based on either the assumption of a periodic distribution or the assumption of a dilute distribution. They calculated the elastic constants of collagen and hydroxyapatite minerals associated with water by using rules of mixture. The hydroxyapatite particles were assumed to be periodically distributed around the long axes of collagen fibrils. Both collagen and hydroxyapa- 
tite where considered as isotropic. Wang et al. [51] developed a mechanical model to simulate peritubular reinforcement effect of porous dentine tubules and observed that overall dentine stiffness increases with thickness of tubules. Recently, Seyedkavoosi and Sevostianov [101] introduced a quantitative multiscale model for elastic properties of dentin as a transversely isotropic material consists of collagen fibers and hydroxyapatite particles. In their model, they considered the different concentrations of hydroxyapatite in tissues of peritubular and intertubular dentins and the tubules are circular cylinders surrounded by layers of peritubular dentin and embedded in intertubular dentin. At each microstructural level, their model accounts for anisotropy of the constituents and showed good agreement with experimental data available in literature.

\section{VISCOELASTIC PROPERTIES OF DENTIN}

Duncanson and Korostoff [102] applied stress relaxation measurements on dentin. According to their results, the relaxation modulus of dentin showed a linear dependence on the logarithm of time during a period of about four decades and that the distribution of relaxation time is constant to a high degree during this interval. Korostoff et al. [103] applied the stress relaxation measurements on thick-walled cylinders of radicular human dentin and showed the mechanical response follows the principles of linear viscoelastic theory. Trengrove et al. [104] studied the stress relaxation properties of moist and air-dried human dentin under compression. They observed under static compressive loading, both moist and air-dried dentin showed a linear stress relaxation with the logarithm of time. Air-dried dentin had a higher stiffness compared to moist dentin and therefore had a higher relaxation modulus. Jantarat et al. [105] studied the creep, stress relaxation and strain rate behavior of human root dentin and showed that the viscoelastic behavior is linear. However, Pashley et al. [106] analyzed the stress-relaxation curves in tension observes the dentin matrix exhibits viscoelastic properties, but it is not linearly viscoelastic. In a later work, Jafarzadeh et al. [107] experimentally determined the viscoelastic characteristics of human dentin under the action of a uniaxial static compressive stress and showed that dentin exhibits a linear viscoelastic response under 'clinical' compressive stress levels with a maximum strain $\sim 1 \%$. Ji and Gao [108] described the mechanical properties including elasticity, viscoelasticity and fracture energy associated with the nanostructure of biological materials including dentin. Petrovic et al. [109] proposed a fractional-derivative viscoelastic model for describing elastic and viscoelastic properties of a human root den- tin and demonstrated it with creep and stress relaxation tests, which accurately matches the experimental results. The analysis provided in the mentioned work is formally mathematical and does not provide any physical guidance regarding the choice of particular values of the model parameters. Wang et al. [98] calculated viscoelastic properties of dentin and modeled it as a transversely isotropic viscoelastic material with known properties containing parallel cylindrical pores. Cui et al. [110] suggested to use a poro-viscoelastic mechanical model to describe dentine with no cracks. The model can predict creep strain, stress relaxation and instant elastic response with anisotropic constitutive relation for porous cylindrical composite materials. Han et al. [111] developed a model for evaluating the mechanical and material properties of dentin tubules with various orientation angles. They showed the determination of the yielding stress, strain, and the elastic modulus is little affected by the loading rate, and the creep behavior of dentin. Singh et al [112] and Singh [113] developed a linear viscoelastic model for collagen-adhesive composite and dentin adhesives and demonstrated the applicability of the model by predicting stress relaxation behavior, frequency-dependent storage and loss moduli, and rate-dependent elastic modulus. Chuang et al. [114] proposed a quantitative approach to characterize the viscoelastic properties of dentin after demineralization, and to examine the elastic properties using a nanoindentation creep test. Seyedkavoosi et al. [115] evaluated the viscoelastic properties of dentin experimentally and presented them using fractional exponential operators.

\section{MICROMECHANICS OF DENTIN}

\subsection{Compliance contribution tensor}

In the context of homogenization problems, the property contribution tensors are used to describe the contribution of a single inhomogeneity into the property of interest - elastic stiffness and compliance, thermal or electrical conductivity and resistivity, diffusion coefficient, etc. Compliance contribution tensors have been first introduced in the context of pores and cracks by [116]. It describes the extra strain produced by the introduction of the inhomogeneity in the otherwise uniform stress field. Sevostianov et al. [117] calculated components of this tensor for a spheroidal inhomogeneity embedded in a transversely isotropic material when the axis of symmetry of the spheroid coincides with the transverse axis of the matrix. We briefly outline the concept of the property contribution tensors below.

We consider a homogeneous elastic material (matrix), with the compliance and stiffness tensors $S^{0}$ and 
$C^{0}$ containing an inhomogeneity of volume $V_{l}$, of a different material with the compliance tensor $S^{1}$ (stiffness tensor $C^{1}$ ). The compliance contribution tensor of the inhomogeneity is a fourth-rank tensor $\boldsymbol{H}$ that gives the extra strain (per reference volume $V$ ) due to the presence of this inhomogeneity:

$$
\Delta \varepsilon_{i j}=\frac{V_{1}}{V} H_{i j k l} \sigma_{k l}^{\infty}
$$

where $\sigma^{\infty}$ is the "remotely applied" stress field that satisfies homogeneous boundary conditions [118], i.e. in absence of the inhomogeneity, it is uniform within its site; the colon denotes contraction over two indices. In the case of multiple inhomogeneities, the extra compliance due to their presence is given by:

$$
\Delta S_{i j k l}=\frac{1}{V} \sum V^{(k)} H_{i j k l}^{(k)} .
$$

Alternatively, one can consider the extra stress $\Delta \sigma$ (over $V$ ) due to an inhomogeneity under uniform displacement boundary conditions (displacements on $\partial V$ that have the form $\left.\boldsymbol{u}\right|_{\partial V}=\varepsilon^{0} \cdot \boldsymbol{n}$ where $\varepsilon^{0}$ is a constant tensor), which defines the stiffness contribution tensor $N$ of an inhomogeneity:

$$
\Delta \sigma_{i j}=\frac{V^{(1)}}{V} N_{i j k l} \varepsilon_{k l}^{0} .
$$

In the case of multiple inhomogeneities, the extra stiffness due to the inhomogeneities is given by:

$$
\Delta C_{i j k l}=\frac{1}{V} \sum V^{(k)} N_{i j k l}^{(k)} .
$$

For an ellipsoidal inhomogeneity, compliance and stiffness contribution tensors have the form:

$$
H=\left[\left(S^{1}-S^{0}\right)^{-1}+Q\right]^{-1} ; N=\left[\left(C^{1}-C^{0}\right)^{-1}+P\right]^{-1},
$$

where Hill's tensor $P_{m n r}$ is calculated in terms of the gradient of the second rank Green's tensor $G_{i j}(\chi-\chi$ ') as

$$
P_{m p i j}(\chi) \equiv \frac{\partial}{\partial \chi_{\underline{\underline{p}}}} \int_{V_{1}} \frac{\partial G_{\underline{m \underline{j}}}\left(\chi-\chi^{\prime}\right)}{\partial \chi_{\underline{\underline{i}}}^{\prime}} \mathrm{d} \chi^{\prime},
$$

where the underlines and double underlines at the subscripts denote symmetrization with respect to $m \leftrightarrow p$ and $i \leftrightarrow j$; Hill's tensor has the same symmetry as the tensor of elastic constants:

$$
P_{i j k l}=P_{j i k l}=P_{i j k}=P_{k l i j}
$$

Second Hill's tensor $\boldsymbol{Q}$ is related to $\boldsymbol{P}$ as follows [119]:

$$
Q_{i j k l}=C_{i j m n}^{0}\left(J_{m n k l}-P_{m n r s} C_{r s k l}^{0}\right) .
$$

Hereafter, $J_{i j k l}=1 / 2\left(\delta_{i k} \delta_{l j}-\delta_{i j} \delta_{k j}\right)$ and the inverse of $\quad$ the symmetric fourth-rank tensor $X_{i j k l}^{-1}$ is defined by $X_{i j m n}^{-1} X_{m n k l}$ $=X_{i j m n} X_{m n k l}^{-1}=J_{i j k l}$. Tensors $\boldsymbol{H}$ and $\boldsymbol{N}$ are interrelated as [120]:

$$
N_{i j k l}=-C_{i j m n}^{0} H_{m n o p} C_{o p k l}^{0} \text {, or, equivalently, } H_{i j k l}=-S_{i j m n}^{0} N_{m n o p} S_{o p k l}^{0} \text {. }
$$

In order to analyze the effect of arbitrarily oriented platelet in a transversely isotropic matrix, in the coordinate system associated with the axes of elastic symmetry of the matrix material, the normal of an arbitrarily oriented platelet can be presented as

$$
\boldsymbol{n}=\sin \varphi \cos \theta \boldsymbol{e}_{1}+\sin \varphi \cos \theta \boldsymbol{e}_{2}+\cos \theta \boldsymbol{e}_{3} .
$$

Hence the cartesian components of compliance contribution tensor of and empty platelet $\boldsymbol{H}^{\text {empty }}(\varphi, \theta)$ imbedded in the transversely isotropic matrix can now be written as follows (see [121]): 


$$
\begin{aligned}
& H_{1111}^{\text {empty }}=4 M_{1} \cos ^{2} \theta \sin ^{2} \varphi ; H_{2222}^{\text {empty }}=4 M_{1} \cos ^{2} \theta \sin ^{2} \varphi ; H_{3333}^{\text {empty }}=2 M_{2} \cos ^{2} \varphi ; \\
& H_{1122}^{\text {empty }}=H_{1133}^{\text {empty }}=H_{2211}^{\text {empty }}=H_{3322}^{\text {empty }}=H_{3311}^{\text {empty }}=0 ; H_{1331}^{\text {empty }}=M_{1} \cos ^{2} \varphi+\frac{1}{2} M_{2} \cos ^{2} \theta \sin ^{2} \varphi ; \\
& H_{1212}^{\text {empty }}=M_{1} \sin ^{2} \varphi ; H_{2332}^{\text {empty }}=M_{1} \cos ^{2} \varphi+\frac{1}{2} M_{2} \sin ^{2} \theta \sin ^{2} \varphi ; H_{1332}^{e m p t y}=\frac{1}{2} M_{2} \cos \theta \sin \theta \cos ^{2} \varphi ; \\
& H_{3112}^{\text {empty }}=M_{1} \cos \varphi \sin \varphi \sin \theta ; \quad H_{1223}^{\text {empty }}=M_{1} \cos \varphi \sin \varphi \cos \theta ; \quad H_{1112}^{\text {empty }}=2 M_{1} \sin ^{2} \varphi \sin \theta \cos \theta ; \\
& H_{1113}^{\text {empty }}=2 M_{1} \sin \varphi \cos \varphi \cos \theta ; \quad H_{2223}^{\text {empty }}=2 M_{1} \sin \varphi \cos \varphi \sin \theta ; \quad H_{2221}^{\text {empty }}=2 M_{1} \sin ^{2} \varphi \sin \theta \cos \theta ; \\
& H_{3331}^{\text {empty }}=M_{2} \cos \theta \sin \varphi \cos \varphi ; H_{3332}^{\text {empty }}=M_{2} \sin \theta \sin \varphi \cos \varphi ; \\
& M_{1}=\frac{G}{\gamma \pi\left[\left(C_{1111} C_{3333}-C_{1133}^{2}\right) \sqrt{C_{2323} / C_{3333}}+\sqrt{C_{2323} C_{1212}} G\right]} ; \quad M_{2}=\frac{G}{\gamma \pi\left(C_{1111} C_{3333}-C_{1133}^{2}\right) \sqrt{C_{2323} / C_{3333}}} ; \\
& G=\sqrt{C_{2323}^{2}+C_{1111} C_{3333}-\left(C_{1133}+C_{2323}\right)^{2}+2 C_{2323} \sqrt{C_{1111} C_{3333}}},
\end{aligned}
$$

where $C_{i j k l}$ is stiffness tensor of the matrix material.

Since the fourth-order Hill's tensors $\boldsymbol{P}$ and $\boldsymbol{Q}$ [122] depend only on the shape of the inhomogeneity and the constants of the matrix material, but not on elastic constants of the inhomogeneity, for the same matrix material we can interrelate the $\boldsymbol{H}$ and $\boldsymbol{N}$ tensors of inhomogeneities of the same shape but having different elastic constants denoted symbolically by "A" and "B" as:

$$
\begin{aligned}
& H_{A}^{-1}-H_{B}^{-1}=\left(S_{A}^{1}-S^{0}\right)^{-1}-\left(S_{B}^{1}-S_{0}\right)^{-1}, \\
& N_{A}^{-1}-N_{B}^{-1}=\left(C_{A}^{1}-C^{0}\right)^{-1}-\left(C_{B}^{1}-C^{0}\right)^{-1} .
\end{aligned}
$$

In particular, if material " $\mathrm{B}$ " is either an empty platelet (pore) or a perfectly rigid material, the replacement relations (12) take the form:

$$
H_{A}^{-1}-H_{\text {pore }}^{-1}=\left(S_{A}-S^{0}\right)^{-1} ; N_{A}^{-1}-N_{\text {rigid }}^{-1}=\left(C_{A}-C^{0}\right)^{-1} .
$$

Thus, the components of compliance and stiffness contribution tensors $\boldsymbol{H}^{\text {filled }}(\varphi, \theta)$ and $\boldsymbol{N}^{\text {filled }}(\varphi, \theta)$ of a platelet in a transversely isotropic matrix can be derived using the replacement relations from formulas (11) (see [121] for detail).

\subsection{Cylindrical pore surrounded by an interphase layer in a transversely isotropic material}

To model the overall properties of dentin, we need one more preliminary result - effect of a cylindrical pore surrounded by a transversely isotropic layer and embedded in a transversely isotropic material with different properties. For a cylindrical inhomogeneity embedded in a transversely isotropic material, where the axis of symmetry of the cylinder is aligned with the axis of symmetry of the matrix, the explicit closed form results for compliance contribution tensor and Hill tensors are derived by [117]:

$$
\begin{aligned}
& H_{1111}=\frac{C_{3333}^{0}\left(2 C_{1133}^{0}+2 C_{1212}^{0}-C_{1111}^{0}-C_{1122}^{0}\right)}{4 C_{1212}^{0}\left(2 C_{1212}^{0} C_{1133}^{0} C_{1133}^{0}-C_{3333}^{0}\left(C_{1111}^{0}+C_{1122}^{0}\right)\right)}+\frac{1}{C_{1111}^{0}+C_{1122}^{0}}+\frac{1}{2 C_{1212}^{0}} ; \\
& H_{1122}=\frac{2 C_{1133}^{0} C_{1133}^{0}-C_{3333}^{0}\left(C_{1111}^{0}+C_{1122}^{0}-2 C_{1212}^{0}\right)}{4 C_{1212}^{0}\left(2 C_{1133}^{0} C_{1133}^{0}-C_{3333}^{0}\left(C_{1111}^{0}+C_{1122}^{0}\right)\right)}-\frac{1}{C_{1111}^{0}+C_{1122}^{0}}+\frac{1}{2 C_{1212}^{0}} \text {; } \\
& H_{1122}=H_{2211} ; H_{1133}=\frac{C_{1133}^{0}}{\left(2 C_{1133}^{0} C_{1133}^{0}-C_{3333}^{0}\left(C_{1111}^{0}+C_{1122}^{0}\right)\right)} ; H_{1133}=H_{3311} \text {; } \\
& H_{2222}=\frac{2 C_{1133}^{0} C_{1133}^{0}-C_{3333}^{0}\left(C_{1111}^{0}+C_{1122}^{0}-2 C_{1212}^{0}\right)}{4 C_{1212}^{0}\left(2 C_{1133}^{0} C_{1133}^{0}-C_{3333}^{0}\left(C_{1111}^{0}+C_{1122}^{0}\right)\right)}+\frac{1}{C_{1111}^{0}+C_{1122}^{0}}+\frac{1}{2 C_{1212}^{0}} \\
& H_{2233}=\frac{C_{1133}^{0}}{2 C_{1133}^{0} C_{1133}^{0}-C_{3333}^{0}\left(C_{1111}^{0}+C_{1122}^{0}\right)} ; H_{2233}=H_{3322} ; H_{3333}=\frac{C_{1111}^{0}+C_{1122}^{0}}{C_{3333}^{0}\left(C_{1111}^{0}+C_{1122}^{0}\right)-2 C_{1133}^{0} C_{1133}^{0}} \text {; } \\
& H_{2323}=\frac{1}{2 C_{1313}^{0}} ; H_{1313}=\frac{1}{2 C_{1313}^{0}} ; \quad H_{1212}=\frac{1}{C_{1111}^{0}+C_{1122}^{0}}+\frac{1}{2 C_{1212}^{0}} \text {, }
\end{aligned}
$$


where $C_{i j k l}^{0}$ is the stiffness tensor of the matrix material.

As explained in the previous section, the compliance and stiffness contribution tensors are interrelated with the properties of the matrix with $N_{i j k l}=-C_{i j m n}^{0} H_{m n o p} C_{o p k l}^{0}$, or, equivalently, $H_{i j k l}=-S_{i j m n}^{0} N_{m n o p} S_{o p k l}^{0}$. In the case of a pore with an interphase layer, we apply the Maxwell homogenization method [123] to calculate effective properties of the cylindrical transversely isotropic composite as:

$$
C_{C y l i j k l}^{E f l}=C_{i j k l}^{0}+\frac{c}{c-1} N_{i j k l},
$$

where $c$ is the volume fraction of the cylindrical pore and the cylindrical matrix:

$$
c=\frac{\pi d^{2} / 2}{\pi D^{2} / 2}
$$

and $d$ and $D$ are the diameter of the pore and the outer layer of the matrix, respectively.

To calculate the stiffness contribution tensor $N$ of the homogenized cylindrical inclusion with effective stiffness (15) embedded in a transversely isotropic matrix with the stiffness tensor $\overline{\boldsymbol{C}}^{0}$ (the axis of the cylinder is aligned with the anisotropy axis of the matrix):

$$
\boldsymbol{N}=\left[\left(\boldsymbol{C}_{C y l}^{E f f}-\overline{\boldsymbol{C}}^{0}\right)^{-1}+\overline{\boldsymbol{P}}^{0}\right]^{-1},
$$

where $\overline{\boldsymbol{P}}^{0}$ is the fourth-order Hill's tensor for cylindrical inclusion in a transversely isotropic matrix (see [117]):

$$
\begin{aligned}
& P_{1111}^{0}=\frac{3}{4\left(\bar{C}_{1111}^{0}+\bar{C}_{1122}^{0}+2 \bar{C}_{1212}^{0}\right)}+\frac{1}{4 \bar{C}_{1212}^{0}} ; P_{1122}^{0}=\frac{1}{4\left(\bar{C}_{1111}^{0}+\bar{C}_{1122}^{0}+2 \bar{C}_{1212}^{0}\right)}-\frac{1}{4 \bar{C}_{1212}^{0}} ; \\
& P_{1122}^{0}=P_{2211}^{0} ; P_{1133}^{0}=0 ; P_{1133}^{0}=P_{3311}^{0} ; P_{2222}^{0}=\frac{1}{4\left(\bar{C}_{1111}^{0}+\bar{C}_{1122}^{0}+2 \bar{C}_{1212}^{0}\right)}+\frac{1}{4 \bar{C}_{1212}^{0}} ; \\
& P_{2233}^{0}=P_{3333}^{0}=0 ; \quad P_{2233}^{0}=P_{3322}^{0} ; P_{2323}^{0}=\frac{1}{8 \bar{C}_{1313}^{0}} ; P_{1313}^{0}=\frac{1}{8 \bar{C}_{1313}^{0}} ; P_{1212}^{0}=\frac{1}{4\left(\bar{C}_{1111}^{0}+\bar{C}_{1122}^{0}+2 \bar{C}_{1212}^{0}\right)}+\frac{1}{4 \bar{C}_{1212}^{0}} .
\end{aligned}
$$

Now formula (17) allows us to write expressions for property contribution tensor of the cylindrical inhomogeneity in the transversely isotropic matrix material.

\subsection{Calculation of the overall elastic properties of dentin}

To calculate overall elastic properties of dentin we use multistep homogenization technique according to Fig. 9. Different steps require different techniques as described below.

Step 1: Calculation of the properties of transversely-isotropic collagen mat (Figs. 9a and 9b). For this goal we average properties of a single collagen fiber over possible orientations. We assume that the fibers in the collagen matrix are randomly oriented in the plane $x_{1} x_{2}$. The elastic stiffness of a single collagen fiber has been evaluated by [124] (local $y_{3}$-axis is the axis of symmetry of a fiber, Fig. 9a):

$$
C_{\text {Collagen fiber }}=\left(\begin{array}{cccccc}
11.7 & 5.1 & 7.1 & 0 & 0 & 0 \\
5.1 & 11.7 & 7.1 & 0 & 0 & 0 \\
7.1 & 7.1 & 17.9 & 0 & 0 & 0 \\
0 & 0 & 0 & 3.3 & 0 & 0 \\
0 & 0 & 0 & 0 & 3.3 & 0 \\
0 & 0 & 0 & 0 & 0 & 3.3
\end{array}\right) \mathrm{GPa}
$$

The data of [124] are obtained on dry collagen and corresponding Young's moduli are about four times higher than those reported in more recent works of [125], [126], and [127]. The latter papers unfortunately do not report the whole set of the elastic constants of collagen that is required. To overcome this problem, we used data of [124] with multiplier 0.25 to make it consistent with above mentioned results: 


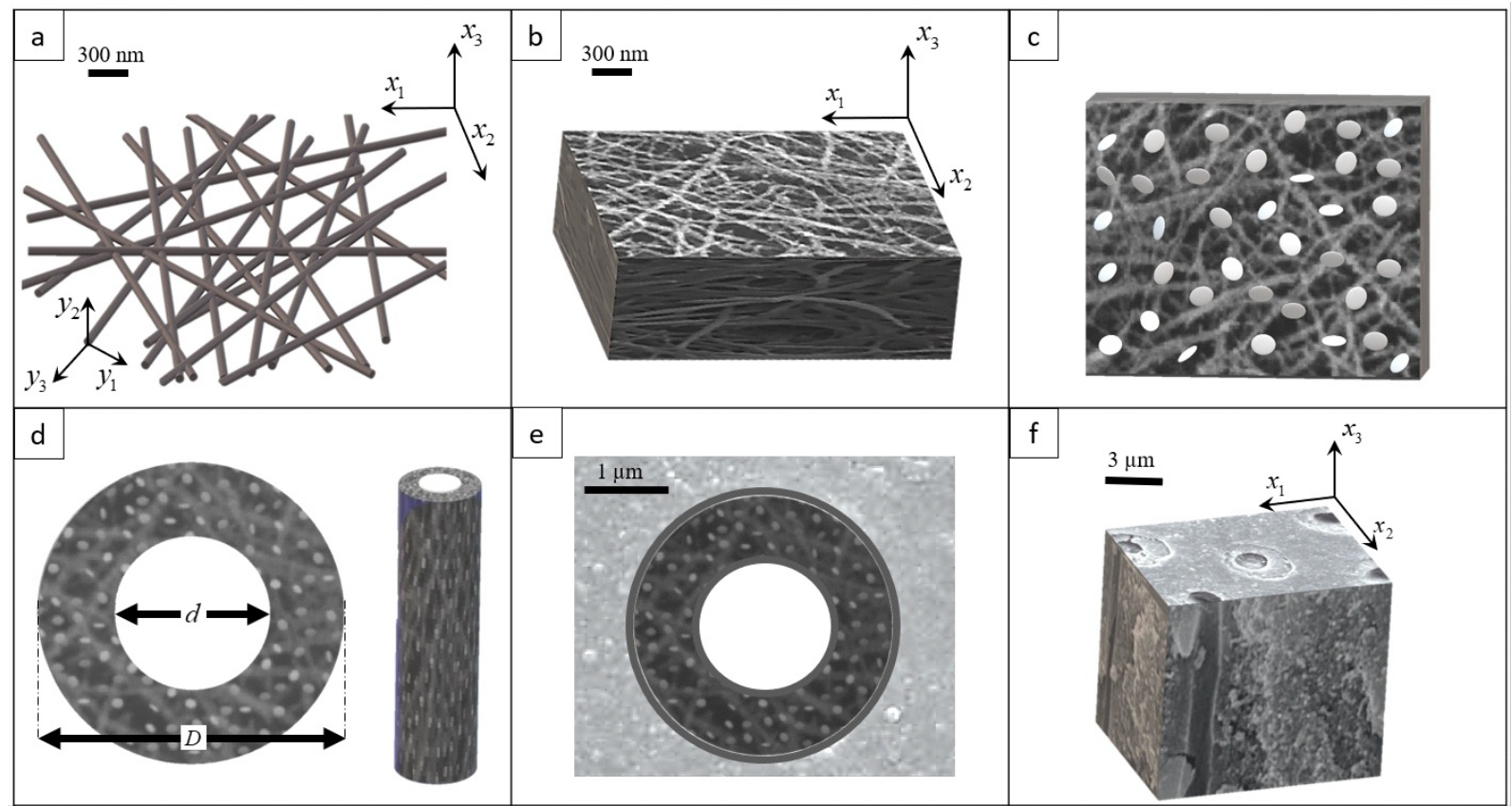

Fig. 9. Multiscale microstructure of dentin: (a) averaging of collagen fibers in $x_{1} x_{2}$ plane, (b) SEM image of demineralized collagen matrix with no hydroxyapatite crystals (reconstructed from 2D images from J. Wang et al., "Remineralization of dentin collagen by meta-stabilized amorphous calcium phosphate," CrystEngComm, vol. 15, no. 31, p. 6151, 2013), (c) schematic view of collagen matrix with randomly oriented hydroxyapatite crystals, (d) schematic view of a tubule with peritubular dentin, (e) schematic view of a tubule with peritubular dentin in intertubular dentin matrix, (f) a 3D SEM image of dentin (reconstructed from 2-D images from T. L. Susin, Alexandre Henrique; Alves, Luana Severo; de Melo, Gliciana Piovesan; Lenzi, "Comparative Scanning Electron Microscopic Study of the Effect of Different Dental,” J. Appl. Oral Sci., vol. 16, no. 2, pp. 100-105, 2008).

$$
C_{\text {Collagen fiber }}=\left(\begin{array}{cccccc}
2.9 & 1.3 & 1.8 & 0 & 0 & 0 \\
1.3 & 2.9 & 1.8 & 0 & 0 & 0 \\
1.8 & 1.8 & 4.5 & 0 & 0 & 0 \\
0 & 0 & 0 & 0.8 & 0 & 0 \\
0 & 0 & 0 & 0 & 0.8 & 0 \\
0 & 0 & 0 & 0 & 0 & 0.8
\end{array}\right) \mathrm{GPa} .
$$

Note that this simplification does not produce noticeable error since effect of collagen on the overall properties of dentin is mild. The result can easily be improved when all elastic constants of collagen are measured. The averaging of $(5.20)$ in the plane $x_{1} x_{2}$ (see, for example $[128,129]$ ) gives the transversely isotropic tensor of elastic stiffness of the collagen matrix where collagen fibers are randomly oriented in the planes parallel to $x_{1} x_{2}$ plane:

$$
C_{\text {Collagen }}=\left(\begin{array}{cccccc}
3.63 & 1.84 & 1.53 & 0 & 0 & 0 \\
1.84 & 3.63 & 1.53 & 0 & 0 & 0 \\
1.53 & 1.53 & 2.93 & 0 & 0 & 0 \\
0 & 0 & 0 & 0.83 & 0 & 0 \\
0 & 0 & 0 & 0 & 0.83 & 0 \\
0 & 0 & 0 & 0 & 0 & 0.89
\end{array}\right) \mathrm{GPa} .
$$

Step 2: Calculation of the properties of collagen-hydroxyapatite composition (Fig. 9c).

Properties of a transversely-isotropic material containing randomly oriented inhomogeneities can be evaluated in closed form if transverse isotropy of the material is of elliptic type [130]. The best fit elliptic transverse isotropy for tensor (21) (see [121]) is given by 


$$
C_{\text {Collagen }}^{\text {ETI }}=\left(\begin{array}{cccccc}
3.62 & 1.84 & 1.55 & 0 & 0 & 0 \\
1.84 & 3.62 & 1.55 & 0 & 0 & 0 \\
1.55 & 1.55 & 2.88 & 0 & 0 & 0 \\
0 & 0 & 0 & 0.85 & 0 & 0 \\
0 & 0 & 0 & 0 & 0.85 & 0 \\
0 & 0 & 0 & 0 & 0 & 0.89
\end{array}\right) \mathrm{GPa} .
$$

and the error of the approximation calculated by the Euclidean norm

$$
\delta=\sqrt{\frac{\left(C_{i j k l}-C_{i j k l}^{E T I}\right)\left(C_{i j k l}-C_{i j k l}^{E T I}\right)}{C_{p q r s} C_{p q r s}}}=0.02 \%,
$$

where $C_{i j k l}$ are the components of the elastic stiffnesses of the real material and $C_{i j k l}^{E T I}$ are their elliptic approximations.

Elastic stiffness of a transversely isotropic hydroxyapatite crystal is given by $[131,132]$ for $6 \mathrm{wt} . \%$ of carbonated hydroxyapatite as

$$
C_{H A}=\left(\begin{array}{cccccc}
126.6 & 52.2 & 53.6 & 0 & 0 & 0 \\
52.2 & 124.5 & 52.8 & 0 & 0 & 0 \\
53.6 & 52.8 & 140 & 0 & 0 & 0 \\
0 & 0 & 0 & 37.1 & 0 & 0 \\
0 & 0 & 0 & 0 & 37.5 & 0 \\
0 & 0 & 0 & 0 & 0 & 35.4
\end{array}\right) \mathrm{GPa} .
$$

In the process of calculation of the overall elastic properties of peritubular dentin and intertubular dentin, we consider them as materials with the same microstructure containing different volume fractions of randomly oriented hydroxyapatite crystals. The basic building block for calculation of the overall elastic properties of these materials is the sum $\sum_{m} V_{m} N_{m} / V$. Using the approach described in Section 5.1 (see [121] for detail)

$$
\frac{1}{V} \sum_{m} V_{m} N_{m}=c\left(\begin{array}{cccccc}
18.9 & 7.2 & 4.2 & 0 & 0 & 0 \\
7.2 & 18.9 & 4.2 & 0 & 0 & 0 \\
4.2 & 4.2 & 8.8 & 0 & 0 & 0 \\
0 & 0 & 0 & 3.4 & 0 & 0 \\
0 & 0 & 0 & 0 & 3.4 & 0 \\
0 & 0 & 0 & 0 & 0 & 5.9
\end{array}\right) \mathrm{GPa} .
$$

where $c=\sum_{m} V_{m} / V$ is the volume fraction of hydroxyapatite particles.

Remark. Summation in (25) that corresponds to averaging of tensor $\boldsymbol{N}$ over all possible orientations leads to an anisotropic tensor. This counterintuitive result is explained by the fact that, due to matrix anisotropy, different orientations enter with different weights in the process of averaging. The same phenomena have been reported by [133] for randomly oriented rectilinear cracks in a 2-D orthotropic material.

To calculate the overall elastic properties of intertubular and peritubular dentin, where volume concentrations of hydroxyapatite particles riches $45 \%$ and $90 \%$ respectively, interaction between the inhomogeneities has to be taken into account. For this goal, we use Maxwell homogenization scheme originally proposed by [134] for the electrical conductivity of a material containing randomly located spherical inhomogeneities. This scheme has been formulated in terms of the property contribution tensors for calculation of effective elastic constants of multiphase materials by Sevostianov and Giraud [123] and Sevostianov [135]. Tensor of overall elastic stiffness is expressed in terms of $\sum_{m} V_{m} N_{m} / V$, Hill's tensors $\boldsymbol{P}_{\Omega}$ for representative volume element $\Omega$, and stiffness tensor $\boldsymbol{C}^{0}$ of the matrix material as follows: 


$$
\boldsymbol{C}^{e f f}=\boldsymbol{C}^{0}+\left\{\left[\frac{1}{V} \sum_{m} V_{m} N_{m}\right]^{-1}-\boldsymbol{P}_{\Omega}\right\}^{-1} .
$$

Since the hydroxyapatite particles are randomly oriented, the shape of domain $\Omega$ is taken as spherical (see [135]) and tensor $\boldsymbol{P}_{\Omega}$ is calculated for a spherical inclusion by formulas (2.52) of [117]. It gives the following result

$$
P=\left(\begin{array}{cccccc}
0.20 & -0.06 & -0.06 & 0 & 0 & 0 \\
-0.06 & 0.20 & -0.06 & 0 & 0 & 0 \\
-0.06 & -0.06 & 0.22 & 0 & 0 & 0 \\
0 & 0 & 0 & 0.14 & 0 & 0 \\
0 & 0 & 0 & 0 & 0.14 & 0 \\
0 & 0 & 0 & 0 & 0 & 0.13
\end{array}\right) \times 10^{-9} \mathrm{~Pa}^{-1}
$$

Fig. 10 illustrates dependences of the overall elastic properties of intertubular and peritubular dentin on the volume concentration of hydroxyapatite crystals. To verify this model, we compare the results of our calculations with the experimental data of Pugach et al. [136] for dense wet dentin tissue obtained by nanoindentation. Fig. 11 shows a comparison of the results predicted by (25) with these experimental data. The agreement of the prediction provided by our model with the experimental data is quite good, $R^{2}=0.76$.
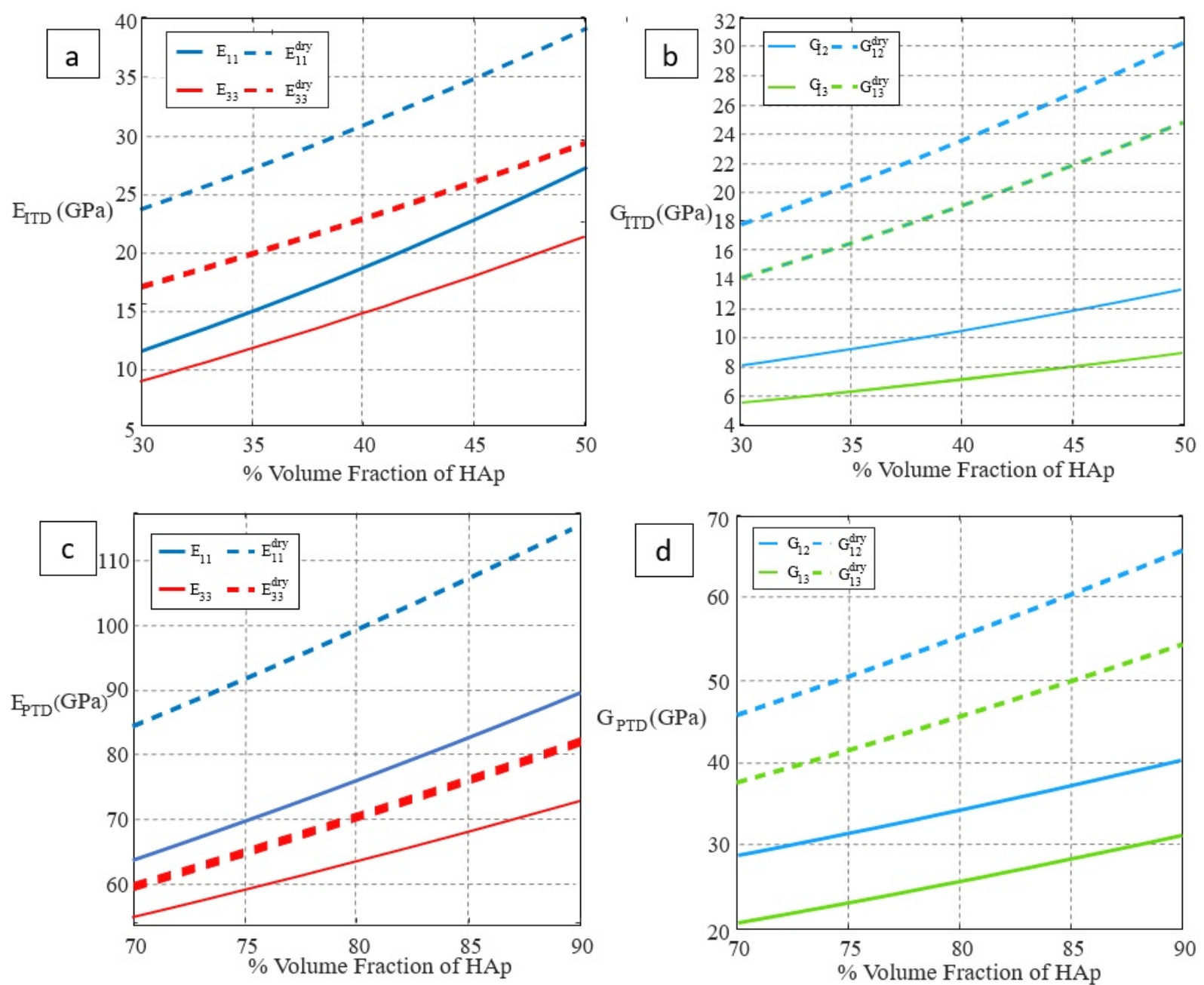

Fig. 10. Youngs modulus and shear modulus of intertubular dentin (ITD) and peritubular dentin (PTD) as a function of hydroxyapatite volume fraction. 


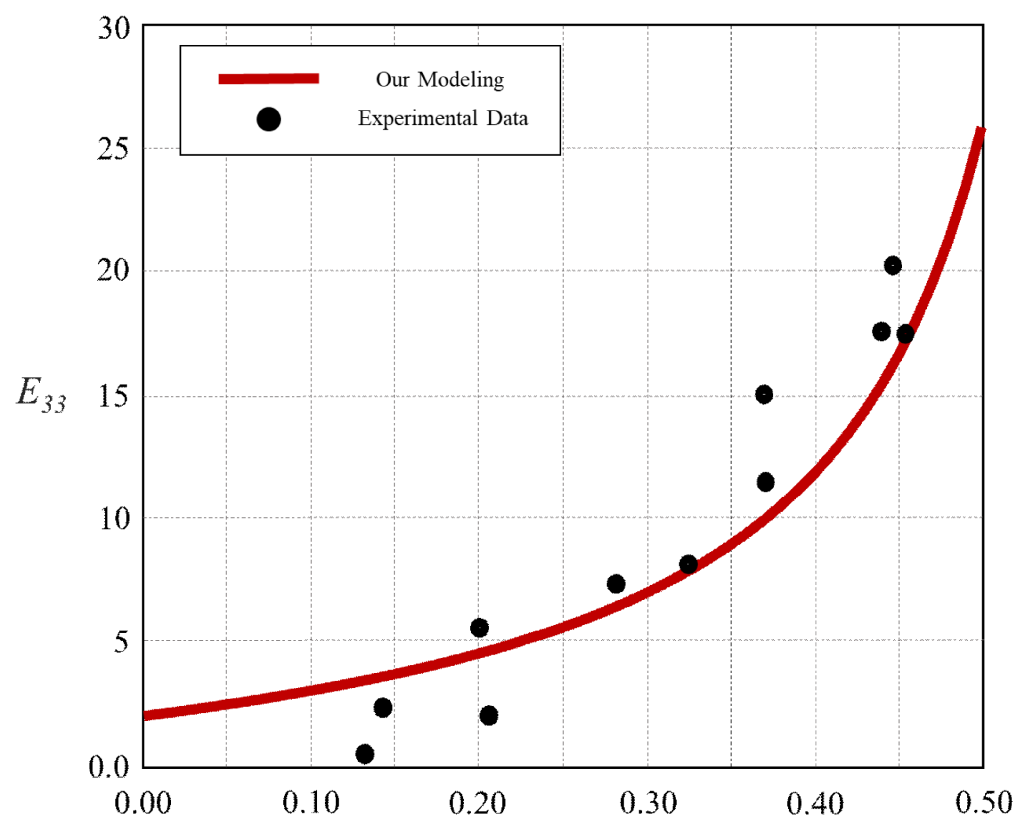

Fig. 11. Comparison of the predicted Young's modulus of wet dentin as a function of volume fraction c of hydroxyapatite with experimental data from M. K. Pugach et al., "Dentin caries zones: Mineral, structure, and properties," $J$. Dent. Res., vol. 88, no. 1, pp. 71-76, 2009.

For the further steps, these volume fractions are taken as $45 \%$ and $90 \%$, respectively. So that for intertubular dentin:

$$
C_{I T D}=\left(\begin{array}{cccccc}
24.6 & 10.31 & 5.2 & 0 & 0 & 0 \\
10.31 & 24.6 & 5.2 & 0 & 0 & 0 \\
5.2 & 5.2 & 14.3 & 0 & 0 & 0 \\
0 & 0 & 0 & 3.7 & 0 & 0 \\
0 & 0 & 0 & 0 & 3.7 & 0 \\
0 & 0 & 0 & 0 & 0 & 7.2
\end{array}\right) \mathrm{GPa}
$$

and for peritubular dentin:

$$
C_{P T D}=\left(\begin{array}{cccccc}
105.9 & 43.8 & 50 & 0 & 0 & 0 \\
43.8 & 100.9 & 50 & 0 & 0 & 0 \\
50 & 50 & 90.5 & 0 & 0 & 0 \\
0 & 0 & 0 & 38.2 & 0 & 0 \\
0 & 0 & 0 & 0 & 38.2 & 0 \\
0 & 0 & 0 & 0 & 0 & 31.5
\end{array}\right) \mathrm{GPa} .
$$

Step 3: Calculation of the effective properties of a peritubular dentin cylinder containing a single tubule (Fig. 9d).

We proceed to find the effective properties of composite cylinders made of peritubular dentin containing a single. Hill's tensor for a cylindrical pore in a transversely-isotropic material was explicitly given by [117]. Substituting this result into expression (2.5) for the stiffness contribution tensor with $\boldsymbol{C}^{1}=0$ and $\boldsymbol{C}^{0}$ given by Eq. (11), one obtains 


$$
N^{T u b}=\left(\begin{array}{cccccc}
-3.42 & -1.64 & -1.66 & 0 & 0 & 0 \\
-1.64 & -3.42 & -1.66 & 0 & 0 & 0 \\
-1.66 & -1.66 & -1.68 & 0 & 0 & 0 \\
0 & 0 & 0 & -0.76 & 0 & 0 \\
0 & 0 & 0 & 0 & -0.76 & 0 \\
0 & 0 & 0 & 0 & 0 & -0.9
\end{array}\right) \times 10^{2} \mathrm{GPa}
$$

To calculate the effective properties of the peritubular dentin cylinder containing a cylindrical pore in the center, we use the average diameter of tubules and the thickness of the peritubular dentin as $1.5 \mu \mathrm{m}$ and $0.8 \mu \mathrm{m}$, respectively $[2,24,28]$. Then, the outer diameter of the composite cylinder is $3.1 \mu \mathrm{m}$ and the volume fraction of the pore is 0.067 . Then, Eq. (15) yields the following value for the effective stiffness tensor of peritubular dentin with a tubule:

$$
C^{T+P T D}=\left(\begin{array}{cccccc}
53.7 & 20 & 24.2 & 0 & 0 & 0 \\
20 & 53.7 & 24.2 & 0 & 0 & 0 \\
24.2 & 24.2 & 60.4 & 0 & 0 & 0 \\
0 & 0 & 0 & 23.7 & 0 & 0 \\
0 & 0 & 0 & 0 & 23.7 & 0 \\
0 & 0 & 0 & 0 & 0 & 16.9
\end{array}\right) \mathrm{GPa}
$$

\section{Step 4: Calculation of the overall properties of dentin (Fig. 9 e,f)}

In the last step, we consider the parallel composite inhomogeneities discussed in Step 3. To be embedded in the intertubular dentin matrix. Axis $x_{3}$ is chosen along the axes of the inhomogeneities. From Eq. (17), the compliance contribution tensor $N$ of this cylindrical inhomogeneity in is

$$
N^{\text {PTD +Tub }}=\left(\begin{array}{cccccc}
5.33 & 3.37 & 8.01 & 0 & 0 & 0 \\
3.37 & 5.33 & 8.01 & 0 & 0 & 0 \\
8.01 & 8.01 & 14.8 & 0 & 0 & 0 \\
0 & 0 & 0 & 5.82 & 0 & 0 \\
0 & 0 & 0 & 0 & 5.82 & 0 \\
0 & 0 & 0 & 0 & 0 & 1.0
\end{array}\right) \times 10^{2} \mathrm{GPa}
$$

We now can use expression (26) to calculate effective properties of dentin. Since all the inhomogeneities are parallel to each other, Hill's tensor for representative volume element is the same as for a single inhomogeneity [135]:

$$
P=\left(\begin{array}{cccccc}
0.032 & -0.012 & 0 & 0 & 0 & 0 \\
-0.012 & 0.032 & 0 & 0 & 0 & 0 \\
0 & 0 & 0 & 0 & 0 & 0 \\
0 & 0 & 0 & 0.034 & 0 & 0 \\
0 & 0 & 0 & 0 & 0.034 & 0 \\
0 & 0 & 0 & 0 & 0 & 0.022
\end{array}\right) \times 10^{-9} \mathrm{~Pa}^{-1}
$$

Volume fraction of the cylindrical inhomogeneities is governed by density of tubules per unit area as

$$
v f_{\text {inhomogeneneity }}=\left[\left(d_{\text {tubules }}+2 \times t_{\text {PTD }}\right)^{2} / 4 \times \pi\right] \times N_{\text {tubules }},
$$

where $d_{\text {tubules }}$ is the diameter of tubules, $t_{\text {PTD }}$ is the thickness of the peritubular dentin, and $N_{\text {tubules }}$ is the number of tubules per unit area. The effect of volume fraction of tubules on the effective properties of dentin is presented in Fig. 12. 

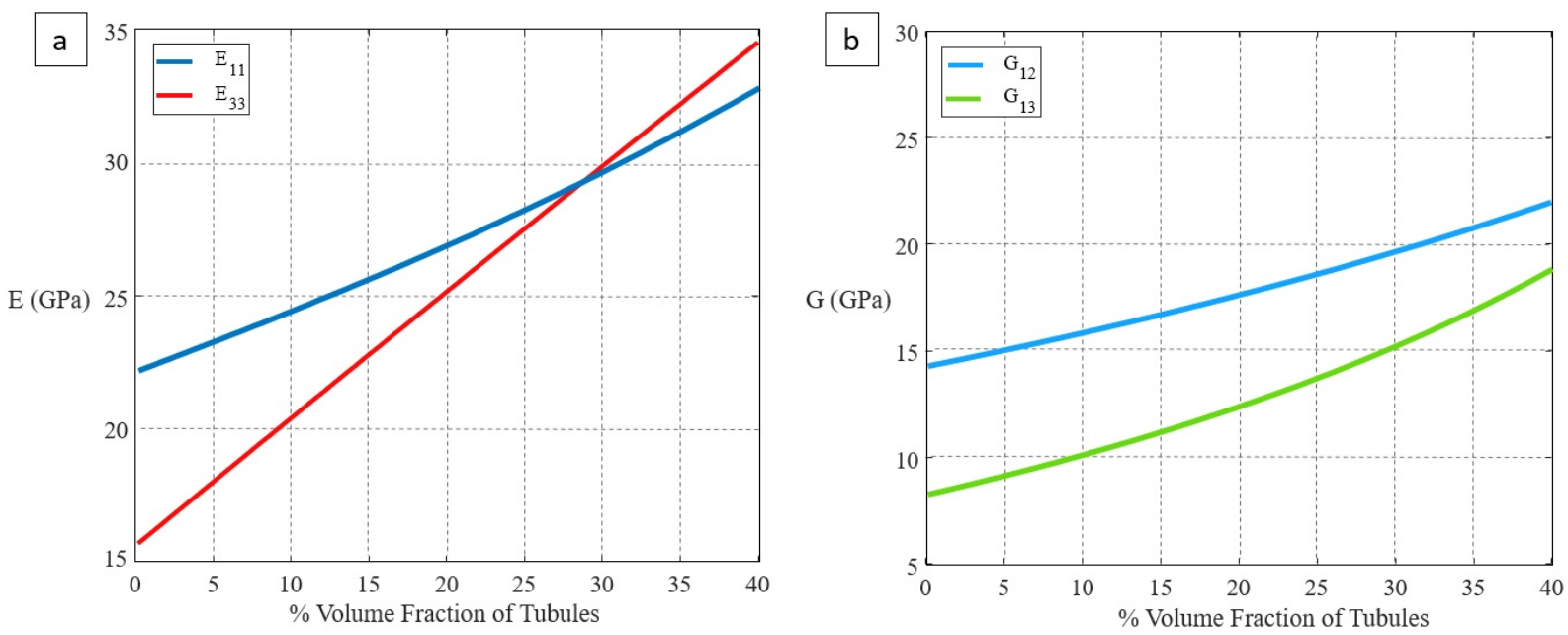

Fig. 12. Overall properties of dentin as a function of volume fraction of dentinal tubules when volume fraction of hydroxyapatite in intertubular dentin and peritubular dentin are $45 \%$ and $90 \%$, respectively. The tubule diameter is $1.5 \mu \mathrm{m}$, and the peritubular dentin thickness is $0.8 \mu \mathrm{m}$.
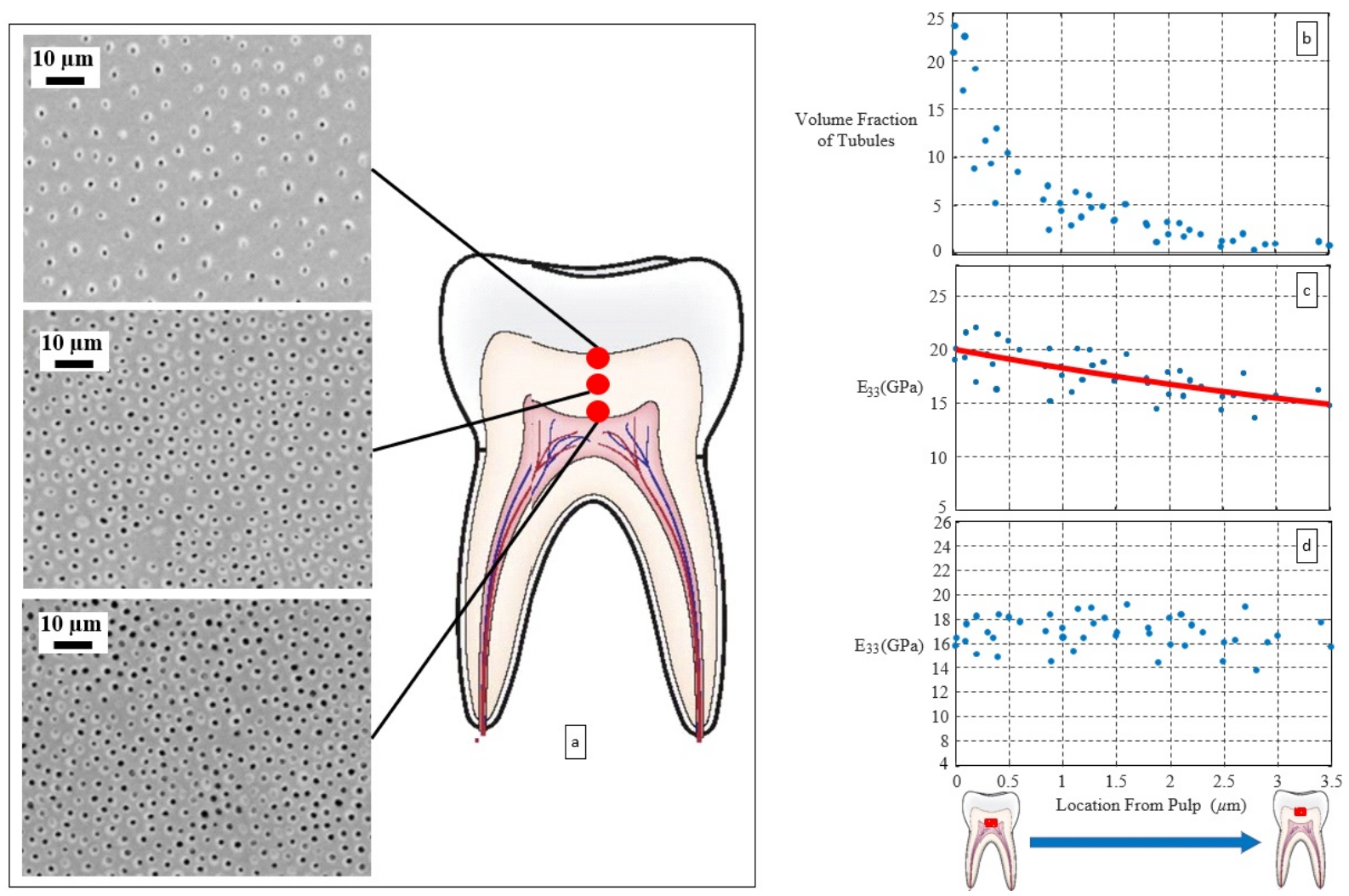

Fig. 13. Variation of the Young's modulus of dentin with the distance from the pulp: (a) variation of the microstructure with the distance; (b) variation of volume fraction of tubules with the distance from the pulp (built on the data from R. Garberoglio and M. Brännström, "Scanning electron microscopic investigation of human dentinal tubules," Arch. Oral Biol., vol. 21, no. 6, pp. 355-362, 1976.) on a number of tubules per unit area and the diameter of tubule using (34); (c) Young's modulus of dentin in the direction of tubules orientation calculated according to Fig. 13b as a function of distance $d$ from pulp. The peritubular dentin thickness is $0.8 \mu \mathrm{m}$. The fitted line is a parabola $E_{33}=0.1036 d^{2}-$ $1.833 d+20.1522$; (d) accounting for the change of the thickness of peritubular dentin layer from 0.6 to $1.0 \mu \mathrm{m}$.

Fig. 13 illustrates variation of the Young's modulus of dentin with the distance from the pulp. Fig. 13a shows variation of the microstructure with this distance. The tubules diameter and density of tubules decrease with location from pulp; the thickness of peritubular dentin, however, increases with location from pulp (from [28]). Fig. $13 \mathrm{~b}$ is built on the data of [2] on a number of tubules per unit area and the diameter of tubule; it illustrates volume fraction of tubules as a function of distance from pulp; data are extracted from. Fig. 13c shows Young's modulus of dentin in the direction of tubules orientation calculated according to Fig. 13b as a function of 
distance $d$ from pulp. The peritubular dentin thickness is $0.8 \mu \mathrm{m}$. The fitted line is a parabola $E_{33}=0.1036 d^{2}$ $1.833 d+20.1522$. It is known, that tubules diameter and density of tubules decrease with location from pulp; however, [28]. Fig. 13d accounts for the change of the thickness of peritubular dentin layer with location from pulp from 0.6 to $1.0 \mu \mathrm{m}$.

\section{CONCLUSIONS}

In the presented paper, our aim was to discuss the latest findings and approaches towards the micromechanical modeling of elastic properties of dentin through mathematical modeling of different dentin microscales and the interactions between them. Different approaches discussed and an accurate and simple way that considers the contributions of all the components including their shape, orientation, and constitutions to dentin's functionality and overall mechanical properties was presented. By categorizing dentin multiscale microstructure along its properties, the results presented in this paper serves as a foundation to guide scientists understand dentin mechanical properties accurately.

\section{REFERENCES}

[1] E. T. Coutinho, J. Roberto, and S. Paciornik, Evaluation of Microstructural Parameters of Human Dentin by Digital Image Analysis, Materials Research, 2007, vol. 10, no. 2, pp. 153-159. http://dx.doi.org/10.1590/S151614392007000200010

[2] R. Garberoglio and M. Brännström, Scanning electron microscopic investigation of human dentinal tubules, Arch. Oral Biol., 1976, vol. 21, no. 6, pp. 355-362. doi:10.1016/s00039969(76)80003-9

[3] E. L. Pashley, R. W. Comer, E. E. Parry, and D. H. Pashley, Amalgam buildups: shear strength and dentin sealing properties, Oper. Dent., 1991, vol. 16, no. 3, pp. 82-89.

[4] N. Mlakar, Z. Pavlica, M. Petelin, J. Štrancar, P. Zrimšek, and A. Pavlič, Animal and human dentin microstructure and elemental composition, Open Medicine, 2014, vol. 9, no. 3. DOI: 10.2478/s11536-013-0295-X

[5] K. J. Chun, H. H. Choi, and J. Y. Lee, Comparison of mechanical property and role between enamel and dentin in the human teeth, Journal of Dental Biomechanics, 2014, pp. 1-7 DOI:10.1177/ 1758736014520809

[6] K. Verdelis, L. Lukashova, J.T. Wright, R. Mendelsohn, and M. G. E. Peterson, Maturational Changes in Dentin Mineral
Properties, Bone, 2007, vol. 40, no. 5, pp. 1399-1407. doi:10.1016/j.bone.2006.12.061

[7] V. Imbeni, J. J. Kruzic, G. W. Marshall, S. J. Marshall, and R. O. Ritchie, The dentin-enamel junction and the fracture of human teeth, Nat. Mater., 2005, vol. 4, no. 3, pp. 229-232. doi:10.1038/ nmat1323

[8] S. P. Ho, M. Balooch, H. E. Goodis, G. W. Marshall, and S. J. Marshall, Ultrastructure and nanomechanical properties of cementum dentin junction, J. Biomed. Mater. Res. - Part A, 2004, vol. 68, no. 2,pp. 343-351. doi:10.1002/jbm.a.20061

[9] C. A. R. Ten, Oral Histology: development, structure, and function, Mosby St Louis, 1998.

[10] Y.-R. Zhang, W. Du, X.-D. Zhou, and H.-Y. Yu, Review of research on the mechanical properties of the human tooth, Int. J. Oral Sci., 2014, vol. 6, no. 2, pp. 61-69. doi:10.1038/ijos.2014.21

[11] R. Halgaš, J. Dusza, J. Kaiferova, L. Kovacsova, and N. Markovska, Nanoindentation testing of human enamel and dentin, Ceramics-Silikáty, 2013, vol. 57, no. 2, pp. 92-99. https:// pdfs.semanticscholar.org/bc17/ 088a2998cafa854382ca026a9d48b3d17894.pdf

[12] J. H. Kinney, R. K. Nalla, J. A. Pople, T. M. Breunig, and R. O. Ritchie, Age-related transparent root dentin: Mineral concentration, crystallite size, and mechanical properties, Biomaterials, 2005, vol. 26, no. 16, pp. 3363-3376. doi:10.1016/j.biomaterials.2004.09.004

[13] G. W. Marshall Jr, S. J. Marshall, J. H. Kinney, and M. Balooch, The dentin substrate: structure and properties related to bonding, J. Dent., 1997, vol. 25, no. 6, pp. 441-458. doi:10.1016/s03005712(96)00065-6

[14] M. Goldberg, Dentin structure composition and mineralization, Front. Biosci., 2011, vol. E3, no. 2, p. 281. doi:10.2741/e281

[15] A. Linde and M. Goldberg, Dentinogenesis, Critical Reviews in Oral Biology \& Medicine, 1993, vol. 4, no. 5, pp. 679-728. https://doi.org/ 10.1177/10454411930040050301

[16] T. Sui, M.A. Sandholzer, N. Baimpas, I.P. Dolbnya, A. Walmsley, P. J. Lumley, G. Landini, A.M. Korsunsky, Multiscale modelling and diffraction-based characterization of elastic behaviour of human dentine, Acta Biomater., 2013, vol.9, no. 8, pp. 7937-7947. doi:10.1016/ j.actbio.2013.04.020

[17] L. E. Bertassoni, J. P. R. Orgel, O. Antipova, and M. V Swain, The dentin organic matrixlimitations of restorative dentistry hidden on the nanometer scale, Acta Biomater., 2012, vol. 8, 
no. 7,pp. 2419-2433. doi:10.1016/

j.actbio.2012.02.022

[18] J. H. Kinney, J. A. Pople, G. W. Marshall, and S. J. Marshall, Laboratory Investigations Collagen Orientation and Crystallite Size in Human Dentin: A Small Angle X-ray Scattering Study, Calcified Tissue International, 2001, vol.69, no.1, pp. 31-37. DOI: 10.1007/s00223-001-0006-5

[19] V. E. Arana-Chavez and L. F. Massa, Odontoblasts: The cells forming and maintaining dentine, Int. J. Biochem. Cell Biol., 2004, vol. 36, no. 8, pp. 1367-1373. doi:10.1016/ s1357-2725(04)00016-0

[20] E. Wentrup-Byrne, C. A. Armstrong, R. S. Armstrong, and B. M. Collins, Fourier transform Raman microscopic mapping of the molecular components in a human tooth, J. Raman Spectrosc., 1997, vol. 28, no. 2-3, pp. 151-158. https://doi.org/10.1002/(SICI)10974555(199702)28:2/3<151::AID-JRS71>3.0.CO;2-5

[21] S. W. Shalaby and U. Salz, Polymers for dental and orthopedic applications. CRC Press, 2006.

[22] S. Jones and A. Boyde, Dentin and Dentinogenesis, CRC Press, Boca Raton, vol. I. 1984.

[23] R. K. Nalla, J. H. Kinney, and R. O. Ritchie, Effect of orientation on the in vitro fracture toughness of dentin: the role of toughening mechanisms, Biomaterials, 2003, vol. 24, no. 22, pp. 3955-3968. doi:10.1016/s0142-9612(03)00278-3

[24] C. Chu, T. Kuo, S. Chang, and Y. Shyu, Comparison of the microstructure of crown and root dentin by a scanning electron microscopic study, Journal of Dental Sciences, 2010, vol. 5, no. 1, pp. 14-20. doi:10.1016/s1991-7902(10)60003-7

[25] Changqi Xu and Yong Wang, Chemical composition and structure of peritubular and intertubular human dentin revisited Changqi, Arch Oral Biol., 2013, vol. 5, no. 4, pp. 383-391. DOI: 10.1016/j.archoralbio.2011.09.008

[26] H. Sicher, Orban's oral histology and embriology. Mosby, 1966.

[27] D. F. Weber, Volume fraction analysis of human coronal dentin, Calcif. Tissue Res., 1969, vol. 4, no. 1, pp. 257-259. DOI: 10.1007/bf02279128

[28] C. Montoya, S. Arango-Santander, A. Peláezvargas, D. Arola, and E. A. Ossa, Effect of aging on the microstructure, hardness and chemical composition of dentin, Arch. Oral Biol., 2015, vol. 60, no. 12,pp. 1811-1820. DOI: 10.1016/ j.archoralbio.2015.10.002

[29] G. V Black, An Investigation of the Physical Characters of the Human Teeth in Relation to their Diseases, and to Practical Dental
Operations, together with the Physical Characters of Filling-materials, Dent. Cosm., 1895, vol. 37, pp. 469-484. https:// quod.lib.umich.edu/d/dencos/ACF8385.0037.001/ 681:232?rgn=main;view=image

[30] R. Craig and F. Peyton, Elastic and mechanical properties of human dentin, J. Dent. Res., 1958, vol. 37, no. D, pp. 710-718. doi:10.1177/ 00220345580370041801

[31] F. Peyton, D. B. Mahler, and B. Hershenov, Physical properties of dentin, J. Dent. Res., 1952, vol. 31, no. 3, pp. 366-370. https://doi.org/ 10.1177/0022034552031003140

[32] J. W. Stanford, G. C. Paffenbarger, J. W. Kumpula, and W. T. Sweeney, Determination of some compressive properties of human enamel and dentin, J. Am. Dent. Assoc., 1958, vol. 57, no. 4, pp. 487-495. doi:10.14219/jada.archive.1958.0194

[33] C. E. Renson and M. Braden, Experimental determination of the rigidity modulus, Poisson's ratio and elastic limit in shear of human dentine, Arch. Oral Biol., 1975, vol. 20, no. 1, pp. 43-IN5. doi:10.1016/0003-9969(75)90150-8

[35] D. Pashley, A. Okabe, and P. Parham, The relationship between dentin microhardness and tubule density, Dent. Traumatol., 1985, vol. 1, no. 5, pp. 176-179. doi:10.1111/j.16009657.1985.tb00653.x

[36] L. G. Watanabe, G. W. Marshall, and S. J. Marshall, Dentin shear strength: effects of tubule orientation and intratooth location, Dental Materials, 1996, vol. 12, no. 2 , pp. 109-115. doi:10.1016/s0109-5641(96)80077-7

[37] V. Lertchirakarn, J. E. A. Palamara, and H. H. Messer, Anisotropy of tensile strength of root dentin, J. Dent. Res., 2001, vol. 80, no. 2, pp. 453-456. doi:10.1177/00220345010800021001

[38] R. M. Carvalho, C. A. Fernandes, R. Villanueva, L. Wang, and D. H. Pashley, Tensile strength of human dentin as a function of tubule orientation and density, J. Adhes. Dent., 200, vol. 3, no. 4, pp. 309-14 1. https://www.ncbi.nlm.nih.gov/pubmed/ 11893046

[39] T. Inoue, H. Takahashi, and F. Nishimura, Anisotropy of tensile strengths of bovine dentin regarding dentinal tubule orientation and location, Dent. Mater. J., 2002, vol. 21, no. 1, pp. 32-43. doi:10.4012/dmj.21.32

[40] D. Arola, J. A. Rouland, and D. Zhang, Fatigue and fracture of bovine dentin, Exp. Mech., 2002, vol. 42, no. 4, pp. 380-388. doi:10.1007/ bf02412142

[41] J. Liu, M. Hattori, K. Hasegawa, M. Yoshinari, E. Kawada, and Y. Oda, Effect of Tubule 
Orientation and Dentin Location on the Microtensile Strength of Bovine t Dentin, Dent. Mater. J., 2002, vol. 21, no. 2, pp. 73-82. DOI: 10.4012/dmj.21.73

[42] N. Iwamoto and N. D. Ruse, Fracture toughness of human dentin. Journal of Biomedical Materials Research Part A, 2003, vol. 66, no. 3, pp. 507-512. doi:10.1002/jbm.a.10005

[43] J. Zheng, Z. R. Zhou, J. Zhang, H. Li, and H. Y. Yu, On the friction and wear behaviour of human tooth enamel and dentin, Wear, 2003, vol. 255, no. 7-12, pp. 967-974. doi:10.1016/s00431648(03)00079-6

[44] D. D. Arola and J. A. Rouland, The effects of tubule orientation on fatigue crack growth in dentin, Journal of Biomedical Materials Research Part A, 2003, vol. 67, no. 1, pp. 78-86. doi:10.1002/ jbm.a.10089

[45] J. H. Kinney, J. R. Gladden, G. W. Marshall, S. J. Marshall, J. H. So, and J. D. Maynard, Resonant ultrasound spectroscopy measurements of the elastic constants of human dentin, J. Biomech., 2004, vol. 37, no. 4, pp. 437-441. doi:10.1016/ j.jbiomech.2003.09.028

[46] R. Wang, Anisotropic fracture in bovine root and coronal dentin, Dent. Mater., 2005, vol. 21, no. 5, pp. 429-436. doi:10.1016/j.dental.2004.07.008

[47] D. D. Arola and R. K. Reprogel, Tubule orientation and the fatigue strength of human dentin, Biomaterials, 2006, vol. 27, no. 9, pp. 2131-2140. doi:10.1016/j.biomaterials.2005.10.005

[48] J. Yan, B. Taskonak, J. A. Platt, and J. J. Mecholsky, Evaluation of fracture toughness of human dentin using elastic-plastic fracture mechanics, J. Biomech., 2008, vol. 41, no. 6, pp. 1253-1259. doi:10.1016/j.jbiomech.2008.01.015

[49] S. Inoue, P. N. Pereira, C. Kawamoto, M.Nakajima, K. Koshiro, J. Tagami, R.M.Carvalho, D.H. Pashley, and H. Sano, Effect of depth and tubule direction on ultimate tensile strength of human coronal dentin, Dental materials journal, 2003, vol. 22, no. 1, pp. 39-47. doi:10.4012/dmj.22.39

[50] J. Ivancik, H. Majd, D. Bajaj, E. Romberg, and D. Arola, Contributions of aging to the fatigue crack growth resistance of human dentin, Acta Biomater., 2012, vol. 8, no. 7,pp. 2737-2746. doi:10.1016/j.actbio.2012.03.046

[51] R. Wang, L. Niu, Q. Li, Q. Liu, and H. Zuo, The peritubular reinforcement effect of porous dentine microstructure, PloS one, 2017, vol. 12, no. 8, e0183982. doi:10.1371/journal.pone.0183982

[52] N. Meredith, M. Sherriff, D. J. Setchell, and S. A.V. Swanson, Measurement of the microhardness and Young's modulus of human enamel and dentine using an indentation technique, Arch. Oral Biol., 1996, vol. 41, no. 6, pp. 539-545. doi:10.1016/0003-9969(96)00020-9

[53] R. Wang and S. Weiner, Human root dentin: Structural anisotropy and Vickers microhardness isotropy, Connect. Tissue Res., 1998, vol. 39, no. 4, pp. 269-279. doi:10.3109/ 03008209809021502

[54] Xu, H. H. K., D. T. Smith, S. Jahanmir, E. Romberg, J. R. Kelly, V. P. Thompson, and E. D. Rekow. Indentation damage and mechanical properties of human enamel and dentin, Journal of dental research, 1998, vol. 77, no. 3, pp. 472-480. doi:10.1177/00220345980770030601

[55] H. Fong, M. Sarikaya, S. N. White, and M. L. Snead, Nano-mechanical properties profiles across dentin-enamel junction of human incisor teeth, Mater. Sci. Eng. C, 1999, vol. 7, no. 2, pp. 119-128. doi:10.1016/s0928-4931(99)00133-2

[56] W. Tesch, N. Eidelman, P. Roschger, F. Goldenberg, K. Klaushofer, and P. Fratzl, Graded microstructure and mechanical properties of human crown dentin, Calcif. Tissue Int., 2001, vol. 69, no. 3, pp. 147-157. doi:10.1007/ s00223-001-2012-z

[57] M. Staninec, G.W. Marshall, J.F. Hilton, D.H. Pashley, S.A. Gansky, S.J. Marshall, and J.H. Kinney, Ultimate tensile strength of dentin: evidence for a damage mechanics approach to dentin failure, Journal of biomedical materials research, 2002, vol. 63, no. 3, pp. 342-345. doi:10.1002/jbm.10230

[58] S. Inoue, P.N. Pereira, C. Kawamoto, M. Nakajima, K. Koshiro, J. Tagami, R.M. Carvalho, D.H. Pashley, and H. Sano, Effect of depth and tubule direction on ultimate tensile strength of human coronal dentin, Dental materials journal, 2003, vol. 22, no. 1, pp. 39-47. doi:10.4012/dmj.22.39

[59] V. Fuentes, L. Ceballos, R. Osorio, M. Toledano, R. M. Carvalho, and D. H. Pashley, Tensile strength and microhardness of treated human dentin, Dent. Mater., 2004, vol. 20, no. 6, pp. 522-529. doi:10.1016/j.dental.2003.05.005

[60] F. Mannocci, P. Pilecki, E. Bertelli, and T. F. Watson, Density of dentinal tubules affects the tensile strength of root dentin, Dent. Mater., 2004, vol. 20, no. 3, pp. 293-296. DOI: 10.1016/ S0109-5641(03)00106-4

[61] S.R. Cohen, N. Apter, S. Jesse, S. Kalinin, D. Barlam, A.I. Peretz, D. Ziskind, and H.D. Wagner, AFM investigation of mechanical properties of dentin, Israel Journal of Chemistry, 
2008, vol. 48, no. 2, pp. 65-72. doi:10.1560/ ijc. 48.2 .65

[62] T. Inoue, M. Saito, M. Yamamoto, K. Debari, K. Kou, F. Nishimura, and T. Miyazaki, Comparison of nanohardness between coronal and radicular intertubular dentin, Dental materials journal, 2009, vol. 28, no. 3, pp. 295-300. DOI: $10.4012 /$ dmj.28.295

[63] J. Ivancik, N. K. Neerchal, E. Romberg, and D. Arola, The reduction in fatigue crack growth resistance of dentin with depth, J. Dent. Res., 2011, vol. 90, no. 8, pp. 1031-1036. doi: 10.1177/ 0022034511408429

[64] H. Ryou, N. Amin, A. Ross, N. Eidelman, D. H. Wang, E. Romberg, and D. Arola, Contributions of microstructure and chemical composition to the mechanical properties of dentin, Journal of Materials Science: Materials in Medicine, 2011, vol. 22, no. 5, pp. 1127-1135. doi:10.1007/s10856011-4293-8

[65] F. Fan, D. Feng, R. Wang, Q. Zhang, and H. Niu, The elasticity coefficients measurement of human dentin based on RUS, BioMed research international, 2017, vol. 2017, Article ID 7852971. https://doi.org/10.1155/2017/7852971

[66] A. Viidik, Function and structure of collagenous tissue: investigations on the tensile strength, general rheology and morphology of tendons and joint ligaments in the rabbit, Doctoral Theses from University of Gothenburg, 1968. https://gupea.ub.gu.se/handle/2077/14944

[67] J. L. Katz, Hard tissue as a composite materialI. Bounds on the elastic behavior, J. Biomech., 1971, vol. 4, no. 5, pp. 455-473. doi:10.1016/00219290(71)90064-9

[68] M. L. Lehman, Tensile Strength of Human Dentin, J. Dent. Res., 1967, vol. 46, no. 1, pp. 197-201. doi:10.1177/00220345670460011001

[69] H. Bo and Z. Quanshui, Effect of dentin tubules on the mechanical properties of dentin. Part I: Stress-strain relations and strength criterion, Acta Mech. Sin., 1999, vol. 15, no. 4, pp. 355-365. https://doi.org/10.1007/BF02487933

[70] G. W. Marshall, S. Habelitzl, R. Gallagher, M. Balooch, G. Baloochl, and S. J. Marshall, Nanomechanical properties of hydrated carious human dentin, Journal of Dental Research, 2001, vol. 80, no. 8, pp. 1768-1771. DOI: $10.1177 /$ 00220345010800081701

[71] J. H. Kinney, S. J. Marshall, and G. W. Marshall, The mechanical properties of human dentin: a critical review and re-evaluation of the dental literature, Crit. Rev. Oral Biol. Med., 2003, vol. 14, no. 1, pp. 13-29. https://www.ncbi.nlm.nih.gov/ pubmed/12764017

[72] B. S. Lee, T. T. Hsieh, D. C. H. Chi, W. H. Lan, and C. P. Lin, The role of organic tissue on the punch shear strength of human dentin, J. Dent., 2004, vol. 32, no. 2, pp. 101-107. https://doi.org/ 10.1016/j.jdent.2003.09.001

[73] J. Yan, B. Taskonak, and J. J. Mecholsky, Fractography and fracture toughness of human dentin, J. Mech. Behav. Biomed. Mater., 2009, vol. 2, no. 5, pp. 478-484. https://doi.org/10.1016/ j.jmbbm.2008.12.002

[74] K. Tonami and H. Takahashi, Effects of aging on tensile fatigue strength of bovine dentin, Dent. Mater. J., 1997, vol. 16, no. 2, pp. 156-169. DOI: 10.4012/dmj.16.156

[75] D. Arola and R. K. Reprogel, Effects of aging on the mechanical behavior of human dentin, Biomaterials, 2005, vol. 26, no. 18, pp. 4051-4061. DOI:10.1016/j.biomaterials.2004.10.029

[76] K. J. Koester, J. W. Ager, and R. O. Ritchie, The effect of aging on crack-growth resistance and toughening mechanisms in human dentin, Biomaterials, 2008, vol. 29, no. 10, pp. 1318-1328. DOI: 10.1016/j.biomaterials.2007.12.008

[77] A. Nazari, D. Bajaj, D. Zhang, E. Romberg, and D. Arola, Aging and the reduction in fracture toughness of human dentin, J. Mech. Behav. Biomed. Mater., 2009, vol. 2, no. 5, pp. 550-559. DOI: 10.1016/j.jmbbm.2009.01.008

[78] H. Ryou, E. Romberg, D. H. Pashley, F. R. Tay, and $\mathrm{D}$. Arola, Importance of age on the dynamic mechanical behavior of intertubular and peritubular dentin, Journal of the mechanical behavior of biomedical materials, 2015, vol. 42, pp. 229-242. doi: 10.1016/j.jmbbm.2014.11.021

[79] H. Sano, B. Ciucchi, and W. G. Matthews, Tensile Properties of Mineralized and Demineralized Human and Bovine Dentin, J. Dent. Res., 1994, vol. 73, no. 6, pp. 1205-1211. DOI: 10.1177/ 00220345940730061201

[80] M. Balooch, S. Habelitz, J. H. Kinney, S. J. Marshall, and G. W. Marshall, Mechanical properties of mineralized collagen fibrils as influenced by demineralization, J. Struct. Biol., 2008, vol. 162, no. 3, pp. 404 410. doi: 10.1016/ j.jsb.2008.02.010

[81] L. E. Bertassoni, S. Habelitz, J. H. Kinney, S. J. Marshall, and G. W. Marshall. Jr., Biomechanical perspective on the remineralization of dentin, Caries Res., 2009, vol. 43, no. 1, pp. 70-77. doi: $10.1159 / 000201593$ 
[82] L. E. Bertassoni, S. Habelitz, M. Pugach, P. C. Soares, S. J. Marshall, and G. W. Marshall, Evaluation of surface structural and mechanical changes following remineralization of dentin, Scanning, 2010, vol. 32, no. 5, pp. 312-319. doi: 10.1002/sca.20199

[83] L. E. Bertassoni, S. Habelitz, S. J. Marshall, and G. W. Marshall, Mechanical recovery of dentin following remineralization in vitro - An indentation study, J. Biomech., 2011, vol. 44, no. 1, pp. 176-181. doi: 10.1016/j.jbiomech.2010.09.005

[84] Y. Chen, J. Wang, J. Sun, C. Mao, W. Wang, H. Pan, R. Tang, and X. Gu, Hierarchical structure and mechanical properties of remineralized dentin, J. Mech. Behav. Biomed. Mater., 2014, vol. 40,pp. 297-306. doi: 10.1016/ j.jmbbm.2014.08.024

[85] M. Balooch, M., I-C. Wu-Magidi, A. Balazs, A. S. Lundkvist, S. J. Marshall, G. W. Marshall, W. J. Siekhaus, and J. H. Kinney, Viscoelastic properties of demineralized human dentin measured in water with atomic force microscope (AFM)-based indentation, Journal of Biomedical Materials Research, 1998, vol. 40, no. 4, pp. 539544. DOI: $10.1002 /$ (sici)10974636(19980615)40:4<539::aid-jbm4>3.0.co;2-g

[86] T. J. Huang, H. Schilder, and D. Nathanson, Effects of moisture content and endodontic treatment on some mechanical properties of human dentin, J Endod, 1992, vol. 18, no. 5, pp. 209-215. DOI: 10.1016/S0099-2399(06)81262-8

[87] M. W. Jameson, J. A. A. Hood, and B. G. Tidmarsh, The effects of dehydration and rehydration on some mechanical properties of human dentine, J. Biomech., 1993, vol. 26, no. 9, pp. 1055-1065. DOI: 10.1016/s0021-9290(05)800053

[88] J. H. Kinney, M. Balooch, S. J. Marshall, G. W. Marshall Jr, and T. P. Weihs, Hardness and Young's modulus of human peritubular and intertubular dentine, Archives of Oral Biology, 1996, vol. 41, no. 1, pp. 9-13. DOI: 10.1016/00039969(95)00109-3

[89] D. Arola and W. Zheng, Hydration and dynamic fatigue of dentin, Journal of Biomedical Materials Research Part A, 2006, vol. 77, no. 1, pp. 148-159. DOI: 10.1002/jbm.a.30634

[90] D. Ziskind, M. Hasday, S. R. Cohen, and H. D. Wagner, Young's modulus of peritubular and intertubular human dentin by nano-indentation tests,” J. Struct. Biol., 2011, vol. 174, no. 1, pp. 23-30. doi: 10.1016/j.jsb.2010.09.010

[91] S. T. Rasmussen and R. E. Patchin, Fracture Properties of Human Enamel and Dentin in an
Aqueous Environment, J. Dent. Res., 1984, vol. 63, no. 12, pp. 1362-1368. DOI: $10.1177 /$ 00220345840630120501

[92] D. C. Watts, O. M. el Mowafy, and A. A. Grant, Temperature-dependence of Compressive Properties of Human Dentin, J. Dent. Res., 1987, vol. 66, no. 1, pp. 29-32. DOI: 10.1177/ 00220345870660010601

[93] M. Hayashi, E.V. Koychev, K. Okamura, A. Sugeta, C. Hongo, K. Okuyama, and S. Ebisu, Heat treatment strengthens human dentin, J. Dent. Res., 2008, vol. 87, no. 8, pp. 762-766. DOI: 10.1177/154405910808700807

[94] M. Hayashi, Y. Furuya, K. Minoshima, M. Saito, K. Marumo, S. Nakashima, C. Hongo, J. Kim, T. Ota, and S. Ebisu, Effects of heating on the mechanical and chemical properties of human dentin, Dent. Mater., 2012, vol. 28, no. 4, pp. 385-391. doi:10.1016/j.dental.2011.11.015

[95] J. H. Kinney, M. Balooch, G. W. Marshall, and S. J. Marshall. A micromechanics model of the elastic properties of human dentine, Archives of oral Biology, 1999, vol. 44, no. 10, pp. 813-822. DOI: 10.1016/s0003-9969(99)00080-1

[96] Q. H. Qin and M. V. Swain, A micro-mechanics model of dentin mechanical properties, Biomaterials, 2004, vol. 25, no. 20, pp. 5081-5090. DOI: 10.1016/j.biomaterials.2003.12.042

[97] Y. Wang and Q. Qin, A generalized self consistent model for effective elastic moduli of human dentine, Composites science and technology, 2007, vol. 67, no. 7-8, pp. 1553-1560. https:// doi.org/10.1016/j.compscitech.2006.07.014

[98] X. Wang, Y. Zhang, and Y. Cui, Evaluation of dentinal viscoelastic properties based on its microstructural characters, Advanced Materials Research, 2008, vol. 32, pp. 229-232. https:// doi.org/10.4028/www.scientific.net/AMR.32.229

[99] B. Bar-on and H. D. Wagner, Enamel and dentin as multi-scale bio-composites, J. Mech. Behav. Biomed. Mater., 2012, vol. 12, pp. 174-183. https:/ /doi.org/10.1016/j.jmbbm.2012.03.007

[100] Y. J. Yoon, Estimation of the elastic constants of dentin, International Journal of Precision Engineering and Manufacturing, 2013, vol. 14, no. 2, pp. 317-322. https://doi.org/10.1007/ s12541-013-0043-9

[101] S. Seyedkavoosi and I. Sevostianov, Multiscale micromechanical modeling of the elastic properties of dentin, J. Mech. Behav. Biomed. Mater., 2019, vol. 100, p. 103397. https://doi.org/ 10.1016/j.jmbbm.2019.103397

[102] M. G. Duncanson and E. Korostoff, Compressive Viscoelastic Properties of Human Dentin/ : I. 
Stress-Relaxation Behavior, J. Dent. Res., 1975, vol. 54, no. 6,pp. 1207-1212. DOI: 10.1177/ 00220345750540061801

[103] E. Korostoff, S. R. Pollack, and M. G. Duncanson, Viscoelastic properties of human dentin, J. Biomed. Mater. Res., 1975, vol. 9, no. 6, pp. 661-674. DOI:10.1002/jbm.820090611

[104] H. G. Trengrove, G. M. Carter, and J. A. A. Hood, Stress relaxation properties of human dentin, Dent. Mater., 1995, vol. 11, no. 5-6, pp. 305-310. https://doi.org/10.1016/0109-5641(95)80025-5

[105] J. Jantarat, J. E. A. Palamara, C. Lindner, and H. H. Messer, Time-dependent properties of human root dentin, Dent. Mater., 2002, vol. 18, no. 6, pp. 486-493. https://doi.org/10.1016/ S0109-5641(01)00074-4

[106] D.H. Pashley, K.A. Agee, J.C. Wataha, F. Rueggeberg, L. Ceballos, K. Itou, M. Yoshiyama, R.M. Carvalho, and F.R. Tay FR, Viscoelastic properties of demineralized dentin matrix, Dent. Mater., 2003, vol. 19, no. 8, pp. 700-706. DOI: 10.1016/s0109-5641(03)00016-2

[107] T. Jafarzadeh, M. Erfan, and D. C. Watts, Creep and viscoelastic behaviour of human dentin, Frontiers in Dentistry, 2004, vol. 1, no. 1, pp. 5-14. http://jdt.tums.ac.ir/index.php/jdt/article/ view/1

[108] B. Ji and H. Gao, Mechanical properties of nanostructure of biological materials, J. Mech. Phys. Solids, 2004, vol. 52, no. 9, pp. 1963-1990. https://doi.org/10.1016/j.jmps.2004.03.006

[109] L. M. Petrovic, D. T. Spasic, and T. M. Atanackovic, On a mathematical model of a human root dentin, Dent. Mater., 2005, vol. 21, no. 2, pp. 125-128. DOI: $10.1016 /$ j.dental.2004.01.004

[110] Y. H. Cui, X. Wang, Y. X. Zhang, and F. J. He, Poro-viscoelastic properties of anisotropic cylindrical composite materials, Philos. Mag., 2010, vol. 90, no. 9, pp. 1197-1212. https:// doi.org/10.1080/14786430903317253

[111] C. F. Han, B. H. Wu, C. J. Chung, S. F. Chuang, W. L. Li, and J. F. Lin, Stress-strain analysis for evaluating the effect of the orientation of dentin tubules on their mechanical properties and deformation behavior, J. Mech. Behav. Biomed. Mater., 2012, vol. 12, pp. 1-8. https:// doi.org/10.1016/j.jmbbm.2012.03.009

[112] V. Singh, A. Misra, R. Parthasarathy, Q. Ye, and P. Spencer, Viscoelastic properties of collagenadhesive composites under water-saturated and dry conditions, J. Biomed. Mater. 2015, Res. Part A, vol. 103, no. 2, pp. 646-657. DOI: 10.1002/ jbm.a.35204
[113] V. Singh, Viscoelastic and fatigue properties of dental adhesives and their impact on dentinadhesive interface durability. $\mathrm{PhD}$ diss., University of Kansas, 2009. https:// kuscholarworks.ku.edu/bitstream/handle/1808/ 5661/Singh_ku_0099M_10700_DATA_1. pdf;jsessionid=1D931EE16E787B0FA07749D927 51A4AC? sequence $=1$

[114] S. F. Chuang, S. Y. Lin, P. J. Wei, C. F. Han, J. F. Lin, and H. C. Chang, Characterization of the elastic and viscoelastic properties of dentin by a nanoindentation creep test, J. Biomech., 2015, vol. 48, no. 10,pp. 2155-2161. doi: 10.1016/ j.jbiomech.2015.01.034

[115] S. Seyedkavoosi, D. Zaytsev, B. Drach, P. Panfilov, M. Yu. Gutkin, and I. Sevostianov, Fraction-exponential representation of the viscoelastic properties of dentin, Int. J. Eng. Sci., 2017, vol. 111, pp. 52-60. https://doi.org/ 10.1016/j.ijengsci.2016.11.005

[116] H. Horii and S. Nemat-Nasser, Overall moduli of solids with microcracks: Load-induced anisotropy, J. Mech. Phys. Solids, 1983, vol. 31, no. 2, pp. 155-171. https://doi.org/10.1016/00225096(83)90048-0

[117] I. Sevostianov, N. Yilmaz, V. Kushch, and V. Levin, Effective elastic properties of matrix composites with transversely-isotropic phases, Int. J. Solids Struct., 2005, vol. 42, no. 2, pp. 455476. https://doi.org/10.1016/j.ijsolstr.2004.06.047

[118] Z. Hashin, Analysis of composite materials- $A$ Survey, J. Appl. Mech, 1983, vol. 50, no. 3, pp. 481-505. https://doi.org/10.1115/1.3167081

[119] L. J. Walpole, On bounds for the overall elastic moduli of inhomogeneous systems - I, J. Mech. Phys. Solids, 1966, vol. 14, no. 3, pp. 151-162. https://doi.org/10.1016/0022-5096(66)90035-4

[120] I. Sevostianov and M. Kachanov, Relations between compliances of inhomogeneities having the same shape but different elastic constants, Int. J. Eng. Sci., 2007, vol. 45, no. 10, pp. 797-806. DOI: 10.1016/j.ijengsci.2007.05.004

[121] S. Seyedkavoosi and I. Sevostianov, Modeling of the overall elastic behavior of a transversely isotropic material reinforced with arbitrarily oriented transversely isotropic platelets, Mechanics of Materials, 2019, vol. 132, pp. 77-85. https://doi.org/10.1016/ j.mechmat.2019.02.004

[122] R. Hill, A self-consistent mechanics of composite materials, J. Mech. Phys. Solids, 1965, vol. 13, no. 4, pp. 213-222. https://doi.org/10.1016/00225096(65)90010-4 
[123] I. Sevostianov and A. Giraud, Generalization of Maxwell homogenization scheme for elastic material containing inhomogeneities of diverse shape, Int. J. Eng. Sci., 2013, vol. 64, pp. 23-36. https://doi.org/10.1016/j.ijengsci.2012.12.004

[124] S. Cusack and A. Miller, Determination of the elastic constants of collagen by Brillouin light scattering, J. Mol. Biol., 1979, vol. 135, no. 1, pp. 39-51. https://doi.org/10.1016/00222836(79)90339-5

[125] S. J. Eppell, B. N. Smith, H. Kahn, and R. Ballarini, Nano measurements with microdevices: mechanical properties of hydrated collagen fibrils, Journal of the Royal Society Interface, 2005, vol. 3, no. 6, pp. 117-121. doi: 10.1098/rsif.2005.0100

[126] M. J. Buehler, Nanomechanics of collagen fibrils under varying cross-link densities: atomistic and continuum studies, Journal of the mechanical behavior of biomedical materials, 2008, vol. 1, no. 1, pp. 59-67. doi: 10.1016/ j.jmbbm.2007.04.001

[127] J. Liu, D. Das, F. Yang, A.G. Schwartz, G.M. Genin, S. Thomopoulos, and I. Chasiotis, Energy dissipation in mammalian collagen fibrils: Cyclic strain-induced damping, toughening, and strengthening, Acta biomaterialia, 2018, vol. 80, pp. 217-227. https:// doi.org/10.1016/j.actbio.2018.09.027

[128] T. Mishurova, S. Cabeza, G. Bruno, and I. Sevostianov, Average phase stress concentrations in multiphase metal matrix composites under compressive loading, International Journal of Engineering Science, 2016, vol. 106, pp. 245-261. https://doi.org/ 10.1016/j.ijengsci.2016.06.004

[129] T. Mishurova, N. Rachmatulin, P. Fontana, T. Oesch, G. Bruno, E. Radi, and I. Sevostianov, Evaluation of the probability density of inhomogeneous fiber orientations by computed tomography and its application to the calculation of the effective properties of a fiberreinforced composite, International Journal of Engineering Science, 2018, vol. 122, pp. 14-29, https://doi.org/10.1016/j.ijengsci.2017.10.002

[130] I. Sevostianov and M. Kachanov, On approximate symmetries of the elastic properties and elliptic orthotropy, Int. J. Eng. Sci., 2008, vol. 46, no. 3, pp. 211-223. https:// doi.org/10.1016/j.ijengsci.2007.11.003

[131] A.C. Deymier, A.K. Nair, B. Depalle, Z. Qin, K. Arcot, C. Drouet, C.H, Yoder, M.J. Buehler, S. Thomopoulos, G.M. Genin, and J.D. Pasteris, Protein-free formation of bone-like apatite:
New insights into the key role of carbonation, Biomaterials, 2017, vol. 127, pp. 75-88. doi: 10.1016/j.biomaterials.2017.02.029

[132] A.C.Deymier, Y. An, J.J. Boyle, A.G. Schwartz, V. Birman, G.M. Genin, S. Thomopoulos, and A.H. Barber, Micro-mechanical Properties of the Tendon-to-Bone Attachment, Acta biomaterialia, 2017, vol 56, pp. 25-35. doi: 10.1016/j.actbio.2017.01.037

[133] C. Mauge and M. Kachanov, Mechanics of Anisotropic Materials with Multiple Cracks, Key Eng. Mater., 1996, vol. 120-121, pp. 3-46. https://doi.org/10.4028/www.scientific.net/ KEM.120-121.3

[134] J. C. Maxwell, A treatise on electricity and magnetism, vol. 1. Clarendon press, 1881.

[135] I. Sevostianov, On the shape of effective inclusion in the Maxwell homogenization scheme for anisotropic elastic composites, Mech. Mater., 2014, vol. 75, pp. 45-59. https:// doi.org/10.1016/j.mechmat.2014.03.003

[136] M. K. Pugach, J. Strother, C. L. Darling, D. Fried, S. A. Gansky, S. J. Marshall, and G. W. Marshall, Dentin caries zones: mineral, structure, and properties, Journal of dental research, 2009, vol. 88, no. 1, pp. 71-76. doi: $10.1177 /$ 0022034508327552

[137] P. Fratzl, Collagen: structure and mechanics, an introduction, In: Fratzl P. (eds) Collagen, pp. 1-13, Springer, Boston, MA. MA, 2008. https:// doi.org/10.1007/978-0-387-73906-9_1

[138] G. Goracci, G. Mori, and M. Baldi, Terminal end of the human odontoblast process: a study using SEM and confocal microscopy, Clin. Oral Investig., 1999, vol. 3, no. 3, pp. 126-132. https:// doi.org/10.1007/s007840050090

[139] P. Zaslansky, S. Zabler, and P. Fratzl, 3D variations in human crown dentin tubule orientation: A phase-contrast microtomography study, Dent. Mater., 2010, vol. 26, no. 1, pp. 1-10. doi: 10.1016/ j.dental.2009.09.007

[140] P. Vallittu, Non-metallic biomaterials for tooth repair and replacement, Elsevier, 2012.

[141] X. Wu, M. L. Mei, Q. Li, C. Y. Cao, J. Chen, and R. Xia, A direct electric field-aided biomimetic mineralization system for inducing the remineralization of dentin collagen matrix, Materials, 2015, vol 8, no. 11, pp. 7889-7899. doi: 10.3390/ma8115433

[142] J. Black and G. Hastings, Handbook of biomaterial properties. Springer Science \& Business Media, 2013. 